\title{
Association between Maternal Zinc Status, Dietary Zinc Intake and Pregnancy Complications: A Systematic Review
}

\author{
Rebecca L. Wilson ${ }^{1,2}$, Jessica A. Grieger ${ }^{1,2}$, Tina Bianco-Miotto ${ }^{1,3}$ and Claire T. Roberts ${ }^{1,2, *}$ \\ 1 Robinson Research Institute, University of Adelaide, Adelaide SA 5005, Australia; \\ rebecca.l.wilson@adelaide.edu.au (R.L.W.); jessica.grieger@adelaide.edu.au (J.A.G.); \\ tina.bianco@adelaide.edu.au (T.B.-M.) \\ 2 Adelaide Medical School, University of Adelaide, Adelaide SA 5005, Australia \\ 3 Waite Research Institute, School of Agriculture, Food and Wine, University of Adelaide, \\ Adelaide SA 5005, Australia \\ * Correspondence: claire.roberts@adelaide.edu.au; Tel.: +61-8-8313-3118
}

Received: 29 August 2016; Accepted: 29 September 2016; Published: 15 October 2016

\begin{abstract}
Adequate zinc stores in the body are extremely important during periods of accelerated growth. However, zinc deficiency is common in developing countries and low maternal circulating zinc concentrations have previously been associated with pregnancy complications. We reviewed current literature assessing circulating zinc and dietary zinc intake during pregnancy and the associations with preeclampsia (PE); spontaneous preterm birth (sPTB); low birthweight (LBW); and gestational diabetes (GDM). Searches of MEDLINE; CINAHL and Scopus databases identified 639 articles and 64 studies were reviewed. In 10 out of 16 studies a difference was reported with respect to circulating zinc between women who gave birth to a LBW infant $(\leq 2500 \mathrm{~g})$ and those who gave birth to an infant of adequate weight $(>2500 \mathrm{~g})$, particularly in populations where inadequate zinc intake is prevalent. In 16 of our 33 studies an association was found between hypertensive disorders of pregnancy and circulating zinc; particularly in women with severe PE (blood pressure $\geq 160 / 110 \mathrm{mmHg}$ ). No association between maternal zinc status and sPTB or GDM was seen; however; direct comparisons between the studies was difficult. Furthermore; only a small number of studies were based on women from populations where there is a high risk of zinc deficiency. Therefore; the link between maternal zinc status and pregnancy success in these populations cannot be established. Future studies should focus on those vulnerable to zinc deficiency and include dietary zinc intake as a measure of zinc status.
\end{abstract}

Keywords: zinc; pregnancy; pregnancy complications; dietary zinc intake; circulating zinc

\section{Introduction}

Adequate maternal nutrition, particularly before and during pregnancy, is imperative to the health of both the mother and child [1,2]. Poor nutrition in pregnancy may lead to inappropriate nutrient partitioning between the mother and fetus, which can be deleterious to the health of both [3]. Each year, 3.5 million deaths in women and children are attributed to undernutrition [4]. Zinc deficiency is predicted to be responsible for $1 \%$ of all deaths globally and $4.4 \%$ of deaths in children aged 6 months to 5 years [5]. The World Health Organization (WHO) prioritized minimizing zinc deficiency in developing nations as part of the Millennium Development Goal 1: to eradicate extreme poverty and hunger [6]. Therefore, understanding the effects of zinc deficiency on pregnancy and fetal growth is very important.

Zinc is an essential component of over 1000 proteins including antioxidant enzymes, metalloenzymes, zinc-binding factors and zinc transporters. These are required for a variety of biological 
processes including carbohydrate and protein metabolism, DNA and RNA synthesis, cellular replication and differentiation, and hormone regulation [7-10]. The importance of zinc to the growth of the fetus is demonstrated by the active transport of zinc across the placenta into the fetal circulation resulting in higher cord blood concentrations compared to those in the maternal circulation [11-14]. Rodent models of severe maternal zinc deficiency show increased rates of fetal loss and congenital malformations in the surviving fetuses [15] as well as reduced fetal growth [16-18], lower implantation rates and impaired placental growth [19], all highlighting the teratogenic effects of zinc deficiency in pregnancy.

Diet is the main factor that determines zinc status [20]. In the United States and Australia, an additional 2-4 mg zinc per day is recommended for pregnant women compared to non-pregnant women [21,22]. It is widely acknowledged that many pregnant women do not meet this recommendation [23-25], particularly in developing countries where diets are often plant-based. Grains and legumes contain a significant amount of phytic acid and phytate binding of zinc limits its absorption in the small intestine, contributing to zinc deficiency [22]. Estimates based on bioavailability of zinc, physiological requirements and predicted zinc absorption suggest the prevalence of zinc deficiency to range from 4\% (European countries including the United Kingdom, Sweden, Germany and France) to $73 \%$ in Bangladesh, India and Nepal [26]. A more recent evaluation, based on similar estimates, also predicted inadequate zinc intakes in over $25 \%$ in populations in Southeast Asia and Africa [27].

A recent Cochrane review assessed the effects of zinc supplementation versus no supplementation (with or without placebo) on the success of pregnancy in 21 randomized controlled trials (RCTs) [28]. It was concluded that zinc supplementation reduced the risk of spontaneous preterm birth (sPTB) by $14 \%$ (RR: $0.86,95 \%$ CI: 0.76-0.97; 16 RCTs) but there was no effect on other outcomes such as stillbirth/neonatal death, birthweight and pregnancy-induced hypertension [28]. However, this review did not include the effects of zinc supplementation on reducing the risk of gestational diabetes (GDM) and analysis of maternal circulating zinc concentrations provides evidence that low maternal zinc may be associated with GDM, as well as preeclampsia (PE), gestational hypertension (GH), sPTB and infant birthweight [24,29]. The association between serum zinc and PE has been reviewed recently [30] but there has been no extensive review that has assessed maternal zinc concentrations with respect to a range of pregnancy complications. Here, we review the current literature based on observational studies assessing the association between maternal zinc status and a number of pregnancy complications in order to determine whether maternal circulating zinc or dietary zinc intake are important factors associated with pregnancy outcome.

\section{Materials and Methods}

\subsection{Eligibility Criteria}

Studies included human prospective cohorts, case-control, longitudinal and cross-sectional studies assessing maternal circulating zinc concentrations and pregnancy complications including PE, eclampsia, GH, GDM, small for gestational age (SGA), intrauterine growth restriction (IUGR; $<10$ th percentile), low-birthweight (LBW; $\leq 2500 \mathrm{~g}$ ) and sPTB. Only studies that measured maternal circulating zinc during pregnancy or at delivery and/or dietary zinc intake at these times were included. Studies that assessed zinc concentrations in placenta, amniotic fluid, in offspring (post-natally), cord blood only and breast milk were excluded. There were no restrictions imposed on age of women included in the studies or on any other population characteristic such as race or body mass index (BMI). Given the heterogeneity of the observational strategies, a meta-analysis was not possible.

\subsection{Information Sources and Search}

The search strategy and procedure was guided by the PRISMA statement [31]. Potential studies were located through electronic databases (Ovid Medline (1946-present), CINAHL (1937-present) and Scopus (1995-present)), as well as manual searches of references in review articles and relevant articles known by the authors. Limits included full text articles written in English and published in academic journals. The last search was performed on 25 August 2016. Search terms and MeSH 
headings in the title, abstract, and index terms, were initially identified in Medline and subsequent key words were used for the remaining databases (Appendix B). Briefly, the search included the following: zinc; dietary zinc; zinc intake; plasma zinc; serum zinc; preeclampsia; eclampsia; gestational hypertension; gestational diabetes mellitus; fetal macrosomia; small for gestational age; intrauterine growth restriction; low birthweight; preterm birth.

\subsection{Data Collection}

An independent search of the literature was performed in April 2015 and again in August 2016. Titles and abstracts were examined independently by two of the authors who documented reasons for excluding full text articles. Any differences between the two reviewers were clarified; a third reviewer resolved any disagreements. If an article appeared in duplicate from two or three of the databases, only the search containing the most relevant and useful information was included. For each eligible study, the following data was extracted: author, year and country of publication; inclusion/exclusion criteria; sample size; zinc measure including sample type, collection time during pregnancy and method of analysis and pregnancy outcome. Most studies did not report on exclusion/inclusion criteria; these were therefore not included in the results table. Values determining zinc status were all converted to $\mu \mathrm{g} / \mathrm{L}$ for easier comparisons between studies (Appendix B).

\section{Results}

Figure 1 outlines the literature search and selection of studies. We identified 635 citations after searching Medline (OVID), CINAHL and Scopus databases. A further seven were added by the authors. After screening the title and abstract, 116 full text papers were read. Of these, 67 studies met the inclusion criteria, including 29 on SGA/LBW (Table 1), 34 on hypertensive disorders of pregnancy (Table 4), 11 on sPTB (Table 3) and 9 on GDM (Table 4). Eleven studies assessed multiple pregnancy outcomes and are included in the relevant pregnancy outcome tables. Table 5 summarizes all included studies and whether there was a positive, negative or no association between zinc status and the pregnancy complication. The included studies were tabulated based on those that measured dietary zinc intake, then those that measured serum/plasma zinc. Globally, the average percentage of people affected by inadequate zinc intake is estimated to be $17.3 \%$ [27]. As dietary consumption of zinc is most influential on zinc status, studies that measured circulating zinc were further categorized based on whether they sampled from countries where inadequate zinc intake has been predicted to affect $<17 \%$ or $\geq 17 \%$ of the population. We did not limit the studies to a specific period during gestation when zinc was measured and this information was not provided in eight studies [32-39]. However, zinc concentrations decline across gestation due to a combination of factors including hemodilution and increased fetal demand [40,41] and this made direct comparison of the studies difficult.

\subsection{Infant Birthweight}

There were four studies that assessed dietary zinc intake and birthweight with three based on women from countries where the estimated prevalence of low dietary zinc intake is $<17 \%$ (Table 1) [42-45]. Lower zinc intake was reported in women from the United Kingdom (UK) who gave birth to an SGA infant compared to those who gave birth to an appropriate-for-gestational-age (AGA) infant (SGA: mean (SEM) 11.3 (0.5) vs. AGA 13.0 (0.6) mg/day, $p<0.05$ ) [45]. This was similar to another study of Indian women that reported lower zinc intakes in women who delivered an infant weighing $<2500 \mathrm{~g}$ compared to those who delivered an infant that was $\geq 2500 \mathrm{~g}$ [42]. Logistic regression analysis in one study from the United States reported daily zinc intake $<6 \mathrm{mg} /$ day to be associated with a 2-fold increase in the risk of delivering a LBW infant (aOR: 2.01, 95\% CI: 1.11-3.66) [44] although dietary zinc intakes $<$ median were not found to be associated with LBW in another study of American women (OR: 1.4, 95\% CI: 0.9-2.1) [43]. While both studies used a $24 \mathrm{~h}$ recall questionnaire to determine zinc intakes, there were differences in ethnicity of the women studied as Neggers et al., [43] predominantly studied African-American women as opposed to Scholl et al. who studied Caucasian women [44]. 
Table 1. Included studies assessing maternal zinc status and birthweight.

\begin{tabular}{|c|c|c|c|}
\hline Author, Country & Sample Size & $\begin{array}{l}\text { Zinc Measure } \\
\text { (1) Sample Type } \\
\text { (2) Time at Which Gestation Diet Was } \\
\text { Assessed or Sample Collected } \\
\text { (3) Method of Analysis }\end{array}$ & Outcome of the Study \\
\hline $\begin{array}{l}\text { [42] Simmer, } \\
\text { United Kingdom a }^{\text {a }}\end{array}$ & $\begin{array}{l}28 \text { SGA } \\
29 \text { uncomplicated }\end{array}$ & $\begin{array}{l}\text { Dietary zinc intake } \\
\text { Third trimester of pregnancy } \\
7 \text { day dietary recall }\end{array}$ & $\begin{array}{l}\downarrow \text { mean (SEM) dietary intake in the SGA mothers compared to the } \\
\text { women with uncomplicated pregnancies. } \\
\text { SGA: } 11.3(0.5) \text { vs. uncomplicated: } 13.0(0.6) \mathrm{mg} / \text { day, } p<0.05\end{array}$ \\
\hline [43] Negandhi, India ${ }^{b}$ & $\begin{array}{l}144 \text { LBW } \\
240 \text { uncomplicated }\end{array}$ & $\begin{array}{l}\text { Dietary zinc intake } \\
26-30 \text { weeks } \\
24 \text { h dietary recall }\end{array}$ & $\begin{array}{l}\downarrow \text { mean dietary zinc intake in women with a LBW infant compared } \\
\text { to those with an uncomplicated pregnancy. } \\
\text { LBW: } 5.39 \mathrm{mg} / \text { day vs. uncomplicated } 6.77 \mathrm{mg} / \mathrm{day}, \boldsymbol{p}<\mathbf{0 . 0 0 1}\end{array}$ \\
\hline $\begin{array}{l}\text { [44] Scholl, } \\
\text { United States }{ }^{c}\end{array}$ & $\begin{array}{l}115 \text { with zinc intake } \leq 6 \mathrm{mg} \text { /day } \\
699 \text { with zinc intake }>6 \mathrm{mg} / \text { day }\end{array}$ & $\begin{array}{l}\text { Dietary zinc intake } \\
28 \text { and } 36 \text { weeks } \\
24 \text { h dietary recall }\end{array}$ & $\begin{array}{l}\text { 2-fold } \downarrow \text { risk of delivering a LBW infant with dietary zinc intake } \\
>6 \text { mg/day. } \\
\text { OR: } \mathbf{2 . 0 1}, \mathbf{9 5} \% \text { CI: } \mathbf{1 . 1 1 - 3 . 6 6}\end{array}$ \\
\hline $\begin{array}{l}\text { [45] Neggers, } \\
\text { United States }\end{array}$ & $\begin{array}{l}180 \text { LBW } \\
1218 \text { uncomplicated }\end{array}$ & $\begin{array}{l}\text { Dietary zinc intake } \\
18 \text { and } 30 \text { weeks } \\
24 \text { h dietary recall using the nutrient data base } \\
\text { developed by the University of Minnesota }\end{array}$ & $\begin{array}{l}\text { NS association between low dietary zinc intake (less than median) } \\
\text { and risk of LBW. } \\
\text { OR: } 1.4,95 \% \text { CI: } 0.9-2.1\end{array}$ \\
\hline \multicolumn{4}{|c|}{ Inadequate dietary zinc intake estimated to affect $<17 \%$ of the studied population } \\
\hline [46] Wang, China ${ }^{\mathrm{b}}$ & $\begin{array}{l}247 \text { with serum zinc }<560 \mu \mathrm{g} / \mathrm{L} \\
2940 \text { with serum zinc } \geq 560 \mu \mathrm{g} / \mathrm{L}\end{array}$ & $\begin{array}{l}\text { Fasting serum zinc } \\
\text { Across gestation } \\
\text { Flame AAS }\end{array}$ & $\begin{array}{l}\uparrow \text { incidence of LBW in the mothers with serum zinc }<560 \mu \mathrm{g} / \mathrm{L} \\
\text { compared to those with serum zinc } \geq 560 \mu \mathrm{g} / \mathrm{L} \text {. } \\
\text { Adjusted RR: } 3.41,95 \% \text { CI: 1.97, 5.91 }\end{array}$ \\
\hline $\begin{array}{l}\text { [47] Voss Jepsen, } \\
\text { Denmark }^{\text {a }}\end{array}$ & $\begin{array}{l}10 \text { SGA } \\
30 \text { uncomplicated }\end{array}$ & $\begin{array}{l}\text { Heparin plasma zinc } \\
\text { Collected at } 35-41 \text { weeks } \\
\text { AAS }\end{array}$ & $\begin{array}{l}\uparrow \text { mean (SD) plasma zinc between SGA mothers and those with } \\
\text { uncomplicated pregnancies. } \\
\text { SGA: } 732 \text { (85) vs. uncomplicated: } 654 \text { (78) } \mu \mathrm{g} / \mathrm{L}, p=0.03\end{array}$ \\
\hline [48] Borella, Italy ${ }^{a}$ & $\begin{array}{l}16 \text { SGA } \\
35 \text { uncomplicated }\end{array}$ & $\begin{array}{l}\text { Heparin plasma zinc } \\
\text { Collected in the third trimester } \\
\text { Flame AAS }\end{array}$ & $\begin{array}{l}\uparrow \text { mean (SD) plasma zinc in SGA women compared to women with } \\
\text { uncomplicated pregnancies. } \\
\text { SGA: } 685.6 \text { (119.6) vs. uncomplicated: } 627.5 \text { (150) } \mu \mathrm{g} / \mathrm{L}, p<0.001\end{array}$ \\
\hline [49] Neggers, USA e & $\begin{array}{l}39 \text { LBW } \\
437 \text { uncomplicated }\end{array}$ & $\begin{array}{l}\text { Serum zinc } \\
\text { Collected across gestation } \\
\text { Flame AAS }\end{array}$ & $\begin{array}{l}\text { 8-fold } \uparrow \text { prevalence of LBW with serum zinc in the lowest quartile } \\
\text { (457.5-797.4 } \mu \mathrm{g} / \mathrm{L} \text { ) compared to the highest }(1039.2-1660.1 \mu \mathrm{g} / \mathrm{L}) \text {. } \\
\text { OR: 8.2, 95\% CI:2.4-27.5 }\end{array}$ \\
\hline [50] Bro, Denmark ${ }^{a}$ & $\begin{array}{l}47 \text { SGA and } 34 \text { preterm } \\
220 \text { uncomplicated }\end{array}$ & $\begin{array}{l}\text { Serum zinc } \\
\text { Collected at delivery } \\
\text { Flame AAS }\end{array}$ & $\begin{array}{l}\text { NS mean (SD) serum zinc levels between SGA and women with } \\
\text { uncomplicated pregnancies. } \\
\text { SGA: } 764.7 \text { (119.6) vs. uncomplicated: } 679.7(98) \mu \mathrm{g} / \mathrm{L}\end{array}$ \\
\hline
\end{tabular}


Table 1. Cont.

\begin{tabular}{|c|c|c|c|}
\hline Author, Country & Sample Size & $\begin{array}{l}\text { Zinc Measure } \\
\text { (1) Sample Type } \\
\text { (2) Time at Which Gestation Diet Was } \\
\text { Assessed or Sample Collected } \\
\text { (3) Method of Analysis }\end{array}$ & Outcome of the Study \\
\hline $\begin{array}{l}\text { [38] Hyvonen-Dabek, } \\
\text { Finland }{ }^{\mathrm{f}}\end{array}$ & $\begin{array}{l}4 \text { SGA } \\
10 \text { uncomplicated }\end{array}$ & $\begin{array}{l}\text { Serum zinc } \\
\text { Collection time not specified } \\
\text { Particle induced X-ray emission }\end{array}$ & $\begin{array}{l}\text { NS mean (SD) serum zinc in SGA women compared to those with } \\
\text { uncomplicated pregnancies. } \\
\text { SGA: } 1270(320) \text { vs. uncomplicated: } 1150(220) \mu \mathrm{g} / \mathrm{L}\end{array}$ \\
\hline [51] Mistry, UK ${ }^{a *}$ & $\begin{array}{l}19 \text { SGA } \\
107 \text { uncomplicated }\end{array}$ & $\begin{array}{l}\text { Heparin plasma zinc } \\
\text { Collected at } 28-32 \text { weeks } \\
\text { Inductively coupled plasma } \\
\text { mass spectrometry }\end{array}$ & $\begin{array}{l}\text { NS in mean }(95 \% \text { CI) plasma zinc between SGA women and those } \\
\text { with uncomplicated pregnancies. } \\
\text { SGA: } 708.1(510.4-905.8) \text { vs. uncomplicated: } 634.4 \\
(580.5-688.2) \mu \mathrm{g} / \mathrm{L}\end{array}$ \\
\hline [52] Tamura, USA $\mathrm{g}$ & $\begin{array}{l}80 \text { SGA } \\
80 \text { uncomplicated }\end{array}$ & $\begin{array}{l}\text { Serum zinc } \\
\text { Collected at } 18 \text { weeks and } 30 \text { weeks } \\
\text { Flame AAS }\end{array}$ & $\begin{array}{l}\text { NS in mean (SD) plasma zinc between SGA and women with } \\
\text { uncomplicated pregnancies at } 18 \text { weeks. } \\
\text { SGA: } 627 \text { (118) vs. uncomplicated: } 667 \text { (98) } \mu \mathrm{g} / \mathrm{L} \\
\text { NS in mean (SD) plasma zinc between SGA and women with } \\
\text { uncomplicated pregnancies at } 30 \text { weeks. } \\
\text { SGA: } 562 \text { (92) vs. uncomplicated: } 575(92) \mu \mathrm{g} / \mathrm{L}\end{array}$ \\
\hline [53] Tamura, USA a & $\begin{array}{l}139 \text { SGA } \\
2038 \text { uncomplicated }\end{array}$ & $\begin{array}{l}\text { Non-fasting heparin plasma zinc } \\
\text { Collected at first prenatal visit ( } 6 \text { to } 34 \text { weeks) } \\
\text { Flame AAS }\end{array}$ & $\begin{array}{l}\text { NS in the prevalence }(n(\%)) \text { of SGA measured between the lowest } \\
\text { quartile and upper } 3 \text { quartiles of zinc. } \\
\text { Highest: } 103(4.4) \text { vs. lowest: } 36(4.8)\end{array}$ \\
\hline [54] Ghosh, China ${ }^{\text {a }}$ & $\begin{array}{l}22 \text { SGA } \\
38 \text { uncomplicated }\end{array}$ & $\begin{array}{l}\text { Serum zinc } \\
\text { Collected within } 24 \mathrm{~h} \text { of delivery } \\
\text { AAS }\end{array}$ & $\begin{array}{l}\text { NS in mean (SD) serum zinc levels between SGA and women with } \\
\text { uncomplicated pregnancies. } \\
\text { SGA: } 508.1 \text { (185.9) vs. uncomplicated: } 542.3(162.8) \mu \mathrm{g} / \mathrm{L}\end{array}$ \\
\hline [55] Cherry, USA ${ }^{b}$ & $\begin{array}{l}29 \text { LBW } \\
230 \text { uncomplicated }\end{array}$ & $\begin{array}{l}\text { Heparin plasma zinc } \\
\text { Collected across gestation } \\
\text { AAS }\end{array}$ & $\begin{array}{l}\text { NS mean (SEM) plasma zinc in mothers with a LBW infant } \\
\text { compared to mothers with uncomplicated pregnancies. } \\
\text { LBW: } 604.9 \text { (22.4) vs. uncomplicated: } 577.2(7.7) \mu \mathrm{g} / \mathrm{L}\end{array}$ \\
\hline [56] Bogden, USA ${ }^{h}$ & $\begin{array}{l}22 \text { LBW } \\
50 \text { uncomplicated }\end{array}$ & $\begin{array}{l}\text { EDTA plasma zinc } \\
\text { Collected at delivery } \\
\text { Flame AAS }\end{array}$ & $\begin{array}{l}\text { NS mean (SEM) plasma zinc in women with a LBW infant } \\
\text { compared to women with uncomplicated pregnancies. } \\
\text { LBW: } 640 \text { (20) vs. uncomplicated: } 620(20) \mu \mathrm{g} / \mathrm{L}\end{array}$ \\
\hline \multicolumn{4}{|c|}{ Inadequate dietary zinc intake estimated to affect $\geq 17 \%$ of the studied population } \\
\hline [57] Atinmo, Nigeria ${ }^{h}$ & $\begin{array}{l}20 \mathrm{LBW} \\
30 \text { uncomplicated }\end{array}$ & $\begin{array}{l}\text { Heparin plasma zinc } \\
\text { Collected at delivery } \\
\text { AAS }\end{array}$ & $\begin{array}{l}\downarrow \text { mean (SD) serum zinc in women with a LBW infant compared to } \\
\text { those with uncomplicated pregnancies. } \\
\text { LBW: } 663.1 \text { (144.6) vs. uncomplicated: } 731.5(\mathbf{2 3 5 . 6 )} \mu \mathrm{g} / \mathrm{L}, p<0.05\end{array}$ \\
\hline
\end{tabular}


Table 1. Cont.

\begin{tabular}{|c|c|c|c|}
\hline Author, Country & Sample Size & $\begin{array}{l}\text { Zinc Measure } \\
\text { (1) Sample Type } \\
\text { (2) Time at Which Gestation Diet Was } \\
\text { Assessed or Sample Collected } \\
\text { (3) Method of Analysis }\end{array}$ & Outcome of the Study \\
\hline [58] Abass, Sudan ${ }^{\mathrm{b}}$ & $\begin{array}{l}50 \text { LBW } \\
50 \text { uncomplicated }\end{array}$ & $\begin{array}{l}\text { Serum zinc } \\
\text { AAS } \\
\text { Atomic absorption spectrometry }\end{array}$ & $\begin{array}{l}\downarrow \text { median (IQR) serum zinc in women with a LBW infant compared to } \\
\text { those with uncomplicated pregnancies. } \\
\text { LBW: } 629 \text { (363-968) vs. uncomplicated } 962 \text { (846-1257) } \mu \mathrm{g} / \mathrm{L}, p<0.001\end{array}$ \\
\hline $\begin{array}{l}\text { [59] Rwebembera, } \\
\text { Tanzania }{ }^{c}\end{array}$ & $\begin{array}{l}81 \text { LBW } \\
84 \text { uncomplicated }\end{array}$ & $\begin{array}{l}\text { EDTA plasma zinc } \\
\text { Collected at delivery } \\
\text { Flame AAS }\end{array}$ & $\begin{array}{l}\text { 3-fold } \downarrow \text { risk of delivering a LBW infant with serum zinc } \geq 392.2 \mu \mathrm{g} / \mathrm{L} \\
\text { OR: } 3.07,95 \% \text { CI: } 1.07-8.97\end{array}$ \\
\hline [60] Bahl, India ${ }^{c}$ & $\begin{array}{l}19 \text { LBW } \\
56 \text { uncomplicated }\end{array}$ & $\begin{array}{l}\text { Serum zinc } \\
\text { Collected at delivery } \\
\text { Flame AAS }\end{array}$ & $\begin{array}{l}\downarrow \text { mean (SD) serum zinc in women with a LBW infant compared to } \\
\text { those with uncomplicated pregnancies. } \\
\text { LBW: } \mathbf{5 5 3} \text { (43) vs. } \mathbf{6 9 2} \text { (95) } \mu \mathrm{g} / \mathrm{L}, p<0.001\end{array}$ \\
\hline [61] Singh, India e & $\begin{array}{l}47 \text { LBW } \\
45 \text { uncomplicated }\end{array}$ & $\begin{array}{l}\text { Serum zinc } \\
\text { Collected at delivery } \\
\text { AAS }\end{array}$ & $\begin{array}{l}\downarrow \text { mean (SD) serum zinc in women with a LBW infant compared to } \\
\text { those with uncomplicated pregnancies. } \\
\text { LBW: } \mathbf{6 2 3} \text { (330) vs. uncomplicated: } 895 \text { (514) } \mu \mathrm{g} / \mathrm{L}, p<0.001\end{array}$ \\
\hline [62] Prema, India e & $\begin{array}{l}23 \text { LBW } \\
208 \text { uncomplicated }\end{array}$ & $\begin{array}{l}\text { Serum zinc } \\
\text { Collected at delivery between 9-11.30 a.m. } \\
\text { Flame AAS }\end{array}$ & $\begin{array}{l}\uparrow \text { mean (SD) serum zinc in mothers with a LBW infant compared to } \\
\text { mothers with an uncomplicated pregnancy. } \\
\text { LBW: } \mathbf{6 6 0} \text { (162) vs. uncomplicated: } \mathbf{6 2 0}(\mathbf{1 4 6 )} \mu \mathrm{g} / \mathrm{L}, \boldsymbol{p}<\mathbf{0 . 0 1}\end{array}$ \\
\hline [63] Badakhsh, Iran ${ }^{b}$ & $\begin{array}{l}30 \text { LBW } \\
110 \text { uncomplicated }\end{array}$ & $\begin{array}{l}\text { Serum zinc } \\
\text { Collected at delivery } \\
\text { AAS }\end{array}$ & $\begin{array}{l}\uparrow \text { mean (SD) serum zinc in mothers with a LBW infant compared to } \\
\text { mothers with an uncomplicated pregnancy. } \\
\text { LBW: } \mathbf{6 8 6 . 2} \text { (204.8) vs. uncomplicated: } \mathbf{5 1 4 . 3} \text { (138.8) } \mu \mathrm{g} / \mathrm{L}, p<\mathbf{0 . 0 0 1}\end{array}$ \\
\hline [64] Goel, India ${ }^{a}$ & $\begin{array}{l}20 \text { LBW } \\
25 \text { uncomplicated }\end{array}$ & $\begin{array}{l}\text { Heparin plasma zinc } \\
\text { Collected at delivery } \\
\text { AAS }\end{array}$ & $\begin{array}{l}\text { NS mean (SD) plasma zinc in women with a LBW infant compared to } \\
\text { those with an uncomplicated pregnancy. } \\
\text { LBW: } 726(61) \text { vs. uncomplicated: } 763(56) \mu \mathrm{g} / \mathrm{L}\end{array}$ \\
\hline $\begin{array}{l}\text { [65] Srivastava, } \\
\text { India } b\end{array}$ & $\begin{array}{l}26 \text { LBW } \\
25 \text { uncomplicated }\end{array}$ & $\begin{array}{l}\text { Heparin plasma zinc } \\
\text { Collected at delivery } \\
\text { Flame AAS }\end{array}$ & $\begin{array}{l}\text { NS mean (SD) plasma zinc between mothers with a LBW infant and } \\
\text { mothers with uncomplicated pregnancies. } \\
\text { LBW: } 6470 \text { (4860) vs. uncomplicated: } 5670(2490) \mu \mathrm{g} / \mathrm{L}\end{array}$ \\
\hline [66] Jeswani, India a & $\begin{array}{l}10 \text { SGA } \\
25 \text { uncomplicated }\end{array}$ & $\begin{array}{l}\text { Serum zinc } \\
\text { Collected at } 28-40 \text { weeks } \\
\text { AAS }\end{array}$ & $\begin{array}{l}\text { NS mean (SD) serum zinc in SGA women compared to those with } \\
\text { uncomplicated pregnancies. } \\
\text { SGA: } 938 \text { (76.2) vs. uncomplicated: } 962.8 \text { (194.8) } \mu \mathrm{g} / \mathrm{L}\end{array}$ \\
\hline
\end{tabular}


Table 1. Cont.

\begin{tabular}{|c|c|c|c|}
\hline Author, Country & Sample Size & $\begin{array}{l}\text { Zinc Measure } \\
\text { (1) Sample Type } \\
\text { (2) Time at Which Gestation Diet Was } \\
\text { Assessed or Sample Collected } \\
\text { (3) Method of Analysis }\end{array}$ & Outcome of the Study \\
\hline [67] George, India a & $\begin{array}{l}65 \text { SGA } \\
51 \text { uncomplicated }\end{array}$ & $\begin{array}{l}\text { Heparin plasma zinc } \\
\text { Collected before labor between } 8-10 \text { a.m. } \\
\text { AAS }\end{array}$ & $\begin{array}{l}\text { NS in mean (SD) plasma zinc between SGA and women with } \\
\text { uncomplicated pregnancies. } \\
\text { SGA: } 675 \text { (90) vs. uncomplicated: } 706.7(139) \mu \mathrm{g} / \mathrm{L}\end{array}$ \\
\hline [68] Akman, Turkey ${ }^{\mathrm{f}}$ & $\begin{array}{l}22 \text { SGA } \\
34 \text { uncomplicated }\end{array}$ & $\begin{array}{l}\text { Serum zinc } \\
\text { Collected at delivery } \\
\text { AAS }\end{array}$ & $\begin{array}{l}\text { NS mean (SD) serum zinc between SGA women and women with } \\
\text { uncomplicated pregnancies. } \\
\text { SGA: } 1218 \text { (543) vs. uncomplicated } 1038 \text { (343) } \mu \mathrm{g} / \mathrm{L}\end{array}$ \\
\hline [69] Ozdemir, Turkey ${ }^{b}$ & $\begin{array}{l}16 \text { LBW } \\
59 \text { uncomplicated }\end{array}$ & $\begin{array}{l}\text { Serum zinc } \\
\text { Collected at } 38-42 \text { weeks } \\
\text { Flame AAS }\end{array}$ & $\begin{array}{l}\text { NS mean (SD) serum zinc between mothers with a LBW infant and } \\
\text { mothers with uncomplicated pregnancies. } \\
\text { Data represented on graphs }\end{array}$ \\
\hline \multicolumn{4}{|c|}{$\begin{array}{l}\text { a SGA defined as }<10 \text { th percentile; }{ }^{\mathrm{b}} \mathrm{LBW} \text { defined as }<2500 \mathrm{~g} ;{ }^{\mathrm{c}} \mathrm{LBW} \text { defined as } \leq 2000 \mathrm{~g} \text {; }{ }^{\mathrm{d}} \mathrm{LBW} \text { defined as }<2750 \mathrm{~g} ;{ }^{\mathrm{e}} \mathrm{LBW} \text { defined as }<2000 ;{ }^{\mathrm{f}} \mathrm{g} \\
\text { as }<10 \text { th percentile based on customised centiles; } \mathrm{g} \text { SGA defined as }<15 \text { th percentile; }{ }^{\mathrm{h}} \mathrm{LBW} \text { defined as } \leq 2500 \mathrm{~g} \text {. Bold print signifies results } \\
\text { Abbreviations: AAS: atomic absorption spectrometry; CI: confidence interval; IQR: interquartile range; LBW: low birth weight; NS: non-signific } \\
\text { deviation; SEM: standard error of the mean; SGA: small for gestational age. } \\
\qquad \text { Table 2. Included studies assessing maternal zinc status and hypertensive disorders of pregnancy. }\end{array}$} \\
\hline Author, Country & SAMPLE SIZE & $\begin{array}{l}\text { Zinc Measure } \\
\text { (1) Sample Type } \\
\text { (2) Time at Which Gestation Diet Was } \\
\text { Assessed or Sample Collected } \\
\text { (3) Method of Analysis }\end{array}$ & Outcome of the Study \\
\hline $\begin{array}{l}\text { [70] Tande, } \\
\text { United States }{ }^{\mathrm{a}, \mathrm{b}}\end{array}$ & $\begin{array}{l}13 \text { hypertensive }(11 \mathrm{PE}+2 \mathrm{GH}) \\
44 \text { uncomplicated }\end{array}$ & $\begin{array}{l}\text { Dietary and supplement intake } \\
\text { First } 3 \text { months of pregnancy } \\
\text { Harvard food frequency questionnaire }\end{array}$ & $\begin{array}{l}\text { NS in mean (SEM) dietary zinc intake between those with and } \\
\text { without gestational hypertension. } \\
\text { Hypertensive: } 16.9 \text { (1.56) vs. uncomplicated: } 15.4(1.03) \mathrm{mg} / \text { day }\end{array}$ \\
\hline \multicolumn{4}{|c|}{ Inadequate dietary zinc intake estimated to affect $<17 \%$ of the studied population } \\
\hline $\begin{array}{l}\text { [71] Lazebnik, } \\
\text { United States }\end{array}$ & $\begin{array}{l}17 \mathrm{PE} \text { and } 14 \text { hypertensive } \\
31 \text { uncomplicated }\end{array}$ & $\begin{array}{l}\text { Plasma zinc } \\
\text { Collected within } 1 \mathrm{~h} \text { of delivery } \\
\text { AAS }\end{array}$ & $\begin{array}{l}\downarrow \text { mean (SD) serum zinc in women with PE when compared to } \\
\text { women with uncomplicated pregnancies. } \\
\text { PE: } \mathbf{4 2 0}(\mathbf{1 0 0 )} \text { vs. uncomplicated: } \mathbf{5 2 0}(\mathbf{1 3 0}) \mu \mathrm{g} / \mathrm{L}, \boldsymbol{p}<\mathbf{0 . 0 5} \\
\text { NS mean (SD) plasma zinc in hypertensive women compared to } \\
\text { those whose pregnancies remained uncomplicated. } \\
\text { Hypertensive: } 530 \text { (110) vs. uncomplicated: } 520(110) \mu \mathrm{g} / \mathrm{L}\end{array}$ \\
\hline
\end{tabular}


Table 2. Cont.

\begin{tabular}{|c|c|c|c|}
\hline Author, Country & SAMPLE SIZE & $\begin{array}{l}\text { Zinc Measure } \\
\text { (1) Sample Type } \\
\text { (2) Time at Which Gestation Diet Was } \\
\text { Assessed or Sample Collected } \\
\text { (3) Method of Analysis }\end{array}$ & Outcome of the Study \\
\hline $\begin{array}{l}\text { [55] Cherry, } \\
\text { United States a }\end{array}$ & $\begin{array}{l}48 \text { toxemic/ hypertensive } \\
207 \text { uncomplicated }\end{array}$ & $\begin{array}{l}\text { Heparin plasma zinc } \\
\text { Collected across gestation } \\
\text { AAS }\end{array}$ & $\begin{array}{l}\downarrow \text { mean (SEM) plasma zinc in women with toxemia/ hypertension } \\
\text { compared to women with uncomplicated pregnancies. } \\
\text { Toxemic: } \mathbf{5 4 1 . 5 ~ ( 1 6 . 8 ) ~ v s . ~ u n c o m p l i c a t e d : ~} 590.7 \text { (8) } \mu \mathrm{g} / \mathrm{L}, p<0.009\end{array}$ \\
\hline [72] Kim, Korea ${ }^{\text {a }}$ & $\begin{array}{l}29 \mathrm{PE} \\
30 \text { uncomplicated }\end{array}$ & $\begin{array}{l}\text { Serum zinc } \\
\text { Collected at delivery } \\
\text { Instrumental neutron activation analysis }\end{array}$ & $\begin{array}{l}\downarrow \text { mean (SEM) serum zinc in mothers with PE compared to women } \\
\text { with uncomplicated pregnancies. } \\
\text { PE: } 700 \text { (200) vs. uncomplicated: } 1900 \text { (500) } \mu \mathrm{g} / \mathrm{L}, \boldsymbol{p}<\mathbf{0 . 0 0 0 1}\end{array}$ \\
\hline $\begin{array}{l}\text { [73] Kiilholma, } \\
\text { Finland c,d }\end{array}$ & $\begin{array}{l}10 \text { mild PE and } 10 \text { severe PE } \\
20 \text { uncomplicated }\end{array}$ & $\begin{array}{l}\text { Serum zinc } \\
\text { Collected at delivery } \\
\text { Particle induced X-ray emission }\end{array}$ & $\begin{array}{l}\downarrow \text { mean (SD) serum zinc in women with mild and severe PE } \\
\text { compared to women with uncomplicated pregnancies. } \\
\text { Mild PE: } 510 \text { (70) and severe PE: } 370 \text { (10) vs. uncomplicated: } \\
630 \text { (90) } \mu \mathrm{g} / \mathrm{L}, p<0.001 \text { for both, respectively } \\
\downarrow \text { mean (SD) serum zinc in women with severe PE compared to } \\
\text { those with mild PE. } \\
\text { Severe PE: } 370 \text { (10) vs. mild PE: } 510 \text { (70) } \mu \mathrm{g} / \mathrm{L}, p<0.005\end{array}$ \\
\hline $\begin{array}{l}\text { [74] Araujo Brito, } \\
\text { Brazil }^{\mathrm{e}}\end{array}$ & $\begin{array}{l}20 \text { mild PE and } 24 \text { severe PE } \\
50 \text { uncomplicated }\end{array}$ & $\begin{array}{l}\text { Fasting sodium citrate plasma zinc } \\
\text { Collected before delivery } \\
\text { Flame AAS }\end{array}$ & $\begin{array}{l}\downarrow \text { mean (SD) plasma zinc in mothers with severe PE compared to } \\
\text { mothers with uncomplicated pregnancies. } \\
\text { Severe PE: } 388 \text { (82) vs. uncomplicated: }(\mathbf{4 8 3}(83) \mu \mathrm{g} / \mathrm{L}, \boldsymbol{p}<\mathbf{0 . 0 5} \\
\text { NS mean (SD) plasma zinc in women with mild PE compared to } \\
\text { women with uncomplicated pregnancies. } \\
\text { Mild PE: } 500 \text { (94) vs. uncomplicated: }(483 \text { (83) } \mu \mathrm{g} / \mathrm{L}\end{array}$ \\
\hline [75] Magri, Malta ${ }^{b}$ & $\begin{array}{l}33 \mathrm{GH} \\
110 \text { uncomplicated }\end{array}$ & $\begin{array}{l}\text { Serum zinc } \\
\text { Collected in third trimester } \\
\text { Electro-thermal AAS }\end{array}$ & $\begin{array}{l}\text { NS in mean (SD) serum zinc between women with GH and women } \\
\text { with uncomplicated pregnancies. } \\
\text { PE: } 606 \text { (80) vs. uncomplicated: } 636(100) \mu g / L\end{array}$ \\
\hline [76] Fenzl, Croatia a,b & $\begin{array}{l}30 \mathrm{PE} \text { and } 30 \mathrm{GH} \\
37 \text { uncomplicated }\end{array}$ & $\begin{array}{l}\text { Fasting serum zinc } \\
\text { Collected at the time of diagnosis } \\
\text { Flame AAS }\end{array}$ & $\begin{array}{l}\text { NS in mean (SD) serum zinc between both women with PE or GH } \\
\text { women and women with uncomplicated pregnancies. } \\
\text { PE: } 603 \text { (93) and GH: } 599 \text { (83) vs. uncomplicated: } 578 \text { (93) } \mu \mathrm{g} / \mathrm{L}\end{array}$ \\
\hline [77] Katz, Israel ${ }^{\mathrm{d}}$ & $\begin{array}{l}43 \text { severe PE } \\
80 \text { uncomplicated }\end{array}$ & $\begin{array}{l}\text { Plasma zinc } \\
\text { Collected immediately after delivery } \\
\text { Inductively coupled plasma mass } \\
\text { spectrometry }\end{array}$ & $\begin{array}{l}\text { NS mean (SD) plasma zinc in mothers with severe PE vs. mothers } \\
\text { with uncomplicated pregnancies. } \\
\text { Severe PE: } 685 \text { (875) vs. uncomplicated: } 534 \text { (139) } \mu \mathrm{g} / \mathrm{L}\end{array}$ \\
\hline
\end{tabular}


Table 2. Cont.

\begin{tabular}{|c|c|c|c|}
\hline Author, Country & SAMPLE SIZE & $\begin{array}{l}\text { Zinc Measure } \\
\text { (1) Sample Type } \\
\text { (2) Time at Which Gestation Diet Was } \\
\text { Assessed or Sample Collected } \\
\text { (3) Method of Analysis }\end{array}$ & Outcome of the Study \\
\hline $\begin{array}{l}\text { [38] Hyvonen-Dabek, } \\
\text { Finland }{ }^{f}\end{array}$ & $\begin{array}{l}10 \text { hypertensive } \\
10 \text { uncomplicated }\end{array}$ & $\begin{array}{l}\text { Serum zinc } \\
\text { Collection time not specified } \\
\text { Particle induced X-ray emission }\end{array}$ & $\begin{array}{l}\text { NS mean (SD) serum zinc in women with PE compared to women with an } \\
\text { uncomplicated pregnancy. } \\
\text { PE: } 1070 \text { (320) and hypertensive: } 1090 \text { (170) vs. uncomplicated: } 1150 \text { (220) }\end{array}$ \\
\hline [48] Borella, Italy a & $\begin{array}{l}24 \text { hypertensive } \\
35 \text { uncomplicated }\end{array}$ & $\begin{array}{l}\text { Heparin plasma zinc } \\
\text { Collected in the third trimester } \\
\text { Flame AAS }\end{array}$ & $\begin{array}{l}\text { NS mean (SD) plasma zinc in the hypertensive women compared to those } \\
\text { who remained uncomplicated. } \\
\text { Hypertensive: } 685.6 \text { (149) vs. uncomplicated: } 627.5(150) \mu \mathrm{g} / \mathrm{L}\end{array}$ \\
\hline $\begin{array}{l}\text { [78] Mistry, } \\
\text { United Kingdom a }\end{array}$ & $\begin{array}{l}244 \mathrm{PE} \\
472 \text { uncomplicated }\end{array}$ & $\begin{array}{l}\text { Non-fasting heparin plasma zinc } \\
\text { Collected at } 15 \text { weeks gestation } \\
\text { Inductively coupled plasma mass } \\
\text { spectrometry }\end{array}$ & $\begin{array}{l}\text { NS median (interquartile range) plasma zinc in women with PE women } \\
\text { compared to those with uncomplicated pregnancies. } \\
\text { PE: } 579.6 \text { (521.1-638.6) vs. uncomplicated: } 575.7(515.6-641.7) \mu \mathrm{g} / \mathrm{L}\end{array}$ \\
\hline $\begin{array}{l}\text { [53] Tamura, } \\
\text { United States }^{\text {a }}\end{array}$ & $\begin{array}{l}271 \text { hypertensive } \\
2038 \text { uncomplicated }\end{array}$ & $\begin{array}{l}\text { Non-fasting heparin plasma zinc } \\
\text { Collected at first prenatal visit ( } 6 \text { to } 34 \text { weeks) } \\
\text { Flame AAS }\end{array}$ & $\begin{array}{l}\text { NS in the prevalence }(n(\%)) \text { of hypertension measured between the lowest } \\
\text { quartile and upper } 3 \text { quartiles of zinc. } \\
\text { Highest: } 205(7.9) \text { vs. Lowest: } 66(7.7)\end{array}$ \\
\hline \multicolumn{4}{|c|}{ Inadequate dietary zinc intake estimated to affect $\geq 17 \%$ of the studied population } \\
\hline $\begin{array}{l}\text { [80] Sarwar, } \\
\text { Bangladesh }^{\text {a }}\end{array}$ & $\begin{array}{l}50 \mathrm{PE} \\
58 \text { uncomplicated }\end{array}$ & $\begin{array}{l}\text { Fasting serum zinc } \\
\text { Collected }>20 \text { weeks gestation } \\
\text { Flame AAS }\end{array}$ & $\begin{array}{l}\downarrow \text { mean (SEM) serum zinc in mothers with PE compared to mothers with } \\
\text { uncomplicated pregnancies. } \\
\text { PE: } \mathbf{7 7 0} \text { (50) vs. uncomplicated: } \mathbf{9 8 0} \text { (30) } \mu \mathrm{g} / \mathrm{L}, \boldsymbol{p}<\mathbf{0 . 0 0 1}\end{array}$ \\
\hline [34] Kumru, Turkey a & $\begin{array}{l}30 \mathrm{PE} \\
30 \text { uncomplicated }\end{array}$ & $\begin{array}{l}\text { Serum zinc } \\
\text { Collection time not specified } \\
\text { AAS }\end{array}$ & $\begin{array}{l}\downarrow \text { mean serum zinc in women with PE when compared to women with } \\
\text { uncomplicated pregnancies. } \\
\text { Data represented on graphs, } p<\mathbf{0 . 0 0 1}\end{array}$ \\
\hline [81] IIhan, Turkey ${ }^{a}$ & $\begin{array}{l}21 \mathrm{PE} \\
20 \text { uncomplicated }\end{array}$ & $\begin{array}{l}\text { Serum zinc } \\
\text { Collected at } 31-38 \text { weeks } \\
\text { Flame AAS }\end{array}$ & $\begin{array}{l}\downarrow \text { mean (SD) serum zinc in women with PE when compared to those with } \\
\text { an uncomplicated pregnancy. } \\
\text { PE: } 829.4 \text { (289.3) vs. uncomplicated: } \mathbf{1 2 5 1 . 9}(\mathbf{2 4 2 . 3 )} \mu \mathrm{g} / \mathbf{L}, p<0.001\end{array}$ \\
\hline [82] Bakacak, Turkey ${ }^{a}$ & $\begin{array}{l}38 \mathrm{PE} \\
40 \text { uncomplicated }\end{array}$ & $\begin{array}{l}\text { Fasting serum zinc } \\
32-38 \text { weeks } \\
\text { Flame AAS }\end{array}$ & $\begin{array}{l}\downarrow \text { median (max-min) serum zinc in women with PE when compared to } \\
\text { those with an uncomplicated pregnancy. } \\
\text { PE: } 812.4 \text { (1106.5-624) vs. uncomplicated: } 1084.5 \text { (1385.5-881.2) } \mu \mathrm{g} / \mathrm{L} \text {, } \\
p<\mathbf{0 . 0 0 1}\end{array}$ \\
\hline
\end{tabular}


Table 2. Cont.

\begin{tabular}{|c|c|c|c|}
\hline Author, Country & SAMPLE SIZE & $\begin{array}{l}\text { Zinc Measure } \\
\text { (1) Sample Type } \\
\text { (2) Time at Which Gestation Diet Was } \\
\text { Assessed or Sample Collected } \\
\text { (3) Method of Analysis }\end{array}$ & Outcome of the Study \\
\hline [36] Farzin, Iran ${ }^{a}$ & $\begin{array}{l}60 \mathrm{PE} \\
60 \text { uncomplicated }\end{array}$ & $\begin{array}{l}\text { Fasting heparin plasma zinc } \\
\text { Collection time not specified } \\
\text { Flame AAS }\end{array}$ & $\begin{array}{l}\downarrow \text { mean (SEM) serum zinc in mothers with PE compared to } \\
\text { mothers with uncomplicated pregnancies. } \\
\text { PE: } 764.9 \text { (176.2) vs. uncomplicated: } \mathbf{1 0 0 6 . 1} \text { (201.2) } \mu \mathrm{g} / \mathrm{L}, p<0.001\end{array}$ \\
\hline $\begin{array}{l}\text { [83] Al-Jameil, } \\
\text { Saudi Arabia }\end{array}$ & $\begin{array}{l}40 \mathrm{PE} \\
40 \text { uncomplicated }\end{array}$ & $\begin{array}{l}\text { Serum zinc } \\
\text { Collected in the third trimester } \\
\text { Inductively coupled plasma optical emission } \\
\text { spectrometry }\end{array}$ & $\begin{array}{l}\downarrow \text { mean (SD) serum zinc in mothers with PE compared to mothers } \\
\text { with uncomplicated pregnancies. } \\
\text { PE: } 670 \text { (590) vs. uncomplicated: } 1300 \text { (830) } \mu \mathrm{g} / \mathrm{L}, p<0.05\end{array}$ \\
\hline $\begin{array}{l}\text { [33] Akinloye, } \\
\text { Nigeria a }^{a}\end{array}$ & $\begin{array}{l}49 \mathrm{PE} \\
40 \text { uncomplicated }\end{array}$ & $\begin{array}{l}\text { Serum zinc } \\
\text { Collection time not specified } \\
\text { Flame AAS }\end{array}$ & $\begin{array}{l}\downarrow \text { mean (SD) serum zinc between women with PE and women with } \\
\text { uncomplicated pregnancies. } \\
\text { PE: } \mathbf{5 6 2} \text { (92) vs. uncomplicated: } \mathbf{6 1 4} \text { (52) } \mu \mathrm{g} / \mathrm{L}, \boldsymbol{p}<\mathbf{0 . 0 5}\end{array}$ \\
\hline [39] Jain, India e & $\begin{array}{l}25 \text { mild PE and } 25 \text { severe PE } \\
50 \text { uncomplicated }\end{array}$ & $\begin{array}{l}\text { Serum zinc } \\
\text { Collection time not specified } \\
\text { AAS }\end{array}$ & $\begin{array}{l}\downarrow \text { mean (SD) serum zinc between women with mild PE and those } \\
\text { with uncomplicated pregnancies. } \\
\text { Mild PE: } 831 \text { (111) vs. uncomplicated: } 1022(157) \mu \mathrm{g} / \mathrm{L}, p<0.05 \\
\downarrow \text { mean (SD) serum zinc between women with severe PE and } \\
\text { women with uncomplicated pregnancies. } \\
\text { Severe PE: } 787 \text { (92) vs. uncomplicated: } 1022 \text { (157) } \mu \mathrm{g} / \mathrm{L}, p<0.05\end{array}$ \\
\hline [37] Gupta, India b,e & $\begin{array}{l}47 \text { mild PE and. } 18 \text { severe PE and } \\
10 \text { eclamptic } \\
74 \text { uncomplicated }\end{array}$ & $\begin{array}{l}\text { Non-fasting heparin plasma zinc } \\
\text { Collection time not specified } \\
\text { AAS }\end{array}$ & $\begin{array}{l}\downarrow \text { mean (SD) serum zinc in mothers with severe PE and eclampsia } \\
\text { compared to mothers with uncomplicated pregnancies. } \\
\text { Severe PE: } 607 \text { (107) and eclampsia: } 607 \text { (171) vs. uncomplicated: } \\
\mathbf{6 9 5}(\mathbf{1 1 9 )} \mu \mathrm{g} / \mathrm{L}, \boldsymbol{p}<\mathbf{0 . 0 1} \\
\text { NS in mean (SD) serum zinc between women with mild PE and } \\
\text { women with uncomplicated pregnancies. } \\
\text { Mild PE: } 684 \text { (134) vs. uncomplicated: } 695 \text { (119) } \mu \mathrm{g} / \mathrm{L}\end{array}$ \\
\hline $\begin{array}{l}\text { [84] Bassiouni, } \\
\text { Egypt }{ }^{\text {g,d }}\end{array}$ & $\begin{array}{l}52 \mathrm{PE} \mathrm{(} 28 \text { mild and } 24 \text { severe) } \\
20 \text { uncomplicated }\end{array}$ & $\begin{array}{l}\text { Heparin plasma zinc } \\
\text { Collected at delivery } \\
\text { AAS }\end{array}$ & $\begin{array}{l}\text { NS in mean (SD) plasma zinc in women with mild PE compared to } \\
\text { women with uncomplicated pregnancies. } \\
\text { Mild PE: } 604.2 \text { (162.7) vs. uncomplicated: } 646 \text { (173.7) } \mu \mathrm{g} / \mathrm{L} \\
\downarrow \text { mean (SD) plasma zinc in women with severe PE compared to } \\
\text { the women with uncomplicated pregnancies. } \\
\text { Severe PE: } 410.8 \text { (116.5) vs. uncomplicated: } 646.0(173.7 \mu \mathrm{g} / \mathrm{L} \text {, } \\
p<0.001\end{array}$ \\
\hline
\end{tabular}


Table 2. Cont.

\begin{tabular}{|c|c|c|c|}
\hline Author, Country & SAMPLE SIZE & $\begin{array}{l}\text { Zinc Measure } \\
\text { (1) Sample Type } \\
\text { (2) Time at Which Gestation Diet Was } \\
\text { Assessed or Sample Collected } \\
\text { (3) Method of Analysis }\end{array}$ & Outcome of the Study \\
\hline [85] Harma, Turkey a & $\begin{array}{l}24 \mathrm{PE} \\
44 \text { uncomplicated }\end{array}$ & $\begin{array}{l}\text { Heparin plasma zinc } \\
\text { Collected just during the latent phase of labor } \\
\text { AAS }\end{array}$ & $\begin{array}{l}\uparrow \text { mean (SD) plasma zinc levels in women with PE when compared } \\
\text { to women with uncomplicated pregnancies. } \\
\text { PE: } 15.53 \text { (4.92) vs. uncomplicated: } 11.93(3.11) \mu g / g \text { protein, } \\
p=\mathbf{0 . 0 0 3}\end{array}$ \\
\hline [86] Rafeeinia, Iran h & $\begin{array}{l}35 \mathrm{PE} \text { and } 15 \text { severe } \mathrm{PE} \\
50 \text { uncomplicated }\end{array}$ & $\begin{array}{l}\text { Fasting serum zinc } \\
\text { Collected in the third trimester } \\
\text { AAS }\end{array}$ & $\begin{array}{l}\text { NS mean (SD) serum zinc in mothers with PE or severe PE and } \\
\text { uncomplicated pregnancies. } \\
\text { Mild PE: } 690 \text { (40) and severe PE: } 780 \text { (80) vs. uncomplicated: } \\
720(40) \mu \mathrm{g} / \mathrm{L}\end{array}$ \\
\hline [87] Vafaei, Iran e & $\begin{array}{l}20 \text { mild PE and } 20 \text { severe PE } \\
40 \text { uncomplicated }\end{array}$ & $\begin{array}{l}\text { Serum zinc } \\
\text { Collected at } 28-40 \text { weeks } \\
\text { Auto-analyser }\end{array}$ & $\begin{array}{l}\text { NS mean (SD) serum zinc in either the mild or severe PE women } \\
\text { compared to women with uncomplicated pregnancies. } \\
\text { Data represented on graphs }\end{array}$ \\
\hline $\begin{array}{l}\text { [88] Ahsan, } \\
\text { Bangladesh a,i }\end{array}$ & $\begin{array}{l}44 \mathrm{PE} \text { and } 33 \text { eclampsia } \\
27 \text { uncomplicated }\end{array}$ & $\begin{array}{l}\text { Serum zinc } \\
\text { Collected at } 28-42 \text { weeks } \\
\text { Flame AAS }\end{array}$ & $\begin{array}{l}\text { NS mean (SD) serum zinc in PE or eclamptic women compared to } \\
\text { women with uncomplicated pregnancies. PE: } 1045.8(131) \text { and } \\
\text { eclampsia: } 915 \text { (131) vs. uncomplicated: } 980.4(131) \mu \mathrm{g} / \mathrm{L}\end{array}$ \\
\hline [89] Rathore, India a & $\begin{array}{l}14 \mathrm{PE} \\
47 \text { uncomplicated }\end{array}$ & $\begin{array}{l}\text { Serum zinc } \\
\text { Collected at delivery } \\
\text { Flame AAS }\end{array}$ & $\begin{array}{l}\text { NS mean (SD) serum zinc between women with PE and those with } \\
\text { uncomplicated pregnancies. } \\
\text { PE: } 492 \text { (178) vs. uncomplicated: } 575(216) \mu \mathrm{g} / \mathrm{L}\end{array}$ \\
\hline [90] Kolusari, Turkey ${ }^{\text {a }}$ & $\begin{array}{l}47 \mathrm{PE} \\
48 \text { uncomplicated }\end{array}$ & $\begin{array}{l}\text { Serum zinc } \\
\text { Collected between } 29 \text { and } 38 \text { weeks } \\
\text { AAS }\end{array}$ & $\begin{array}{l}\text { NS mean (SD) serum zinc between women with PE women and } \\
\text { those with uncomplicated pregnancies. } \\
\text { PE: } 10.6 \text { (4.4) vs. uncomplicated: } 12.7(4.1) \mu \mathrm{g} / \mathrm{L}\end{array}$ \\
\hline [91] Atamer, Turkey ${ }^{a}$ & $\begin{array}{l}32 \mathrm{PE} \\
28 \text { uncomplicated }\end{array}$ & $\begin{array}{l}\text { Fasting serum zinc } \\
\text { Collected at } 28-29 \text { weeks } \\
\text { Flame AAS }\end{array}$ & $\begin{array}{l}\text { NS in mean (SD) serum zinc between women with PE and women } \\
\text { with uncomplicated pregnancies. } \\
\text { PE: } 792 \text { (180) vs. uncomplicated: } 1086 \text { (199) } \mu \mathrm{g} / \mathrm{L}\end{array}$ \\
\hline [92] Adam, Turkey a & $\begin{array}{l}20 \mathrm{PE} \\
20 \text { uncomplicated }\end{array}$ & $\begin{array}{l}\text { Plasma zinc } \\
\text { Collected before the onset of labor } \\
\text { Flame AAS }\end{array}$ & $\begin{array}{l}\text { NS mean (SD) plasma zinc in women with PE compared to women } \\
\text { with an uncomplicated pregnancy. } \\
\text { PE: } 313 \text { (47) vs. uncomplicated: } 341 \text { (44) } \mu \mathrm{g} / \mathrm{L}\end{array}$ \\
\hline
\end{tabular}


Table 2. Cont.

\begin{tabular}{|c|c|c|c|}
\hline Author, Country & SAMPLE SIZE & $\begin{array}{l}\text { c Measure } \\
\text { Sample Type } \\
\text { Time at Which Gestation Diet Was Assessed } \\
\text { ample Collected } \\
\text { Method of Analysis }\end{array}$ & Outcome of the Study \\
\hline [93] Vigeh, Iran ${ }^{a}$ & $\begin{array}{l}31 \text { PE } \\
365 \text { uncomplicated }\end{array}$ & $\begin{array}{l}\text { arin plasma zinc } \\
\text { lected at delivery } \\
\text { uctively coupled plasma mass spectrometry }\end{array}$ & $\begin{array}{l}\text { NS mean (SD) plasma zinc between women with PE women and } \\
\text { women with uncomplicated pregnancies. } \\
\text { PE: } 5200 \text { (1444) vs. uncomplicated: } 5561(1057) \mu \mathrm{g} / \mathrm{L}\end{array}$ \\
\hline [32] Adeniyi, Nigeria ${ }^{a}$ & 55 pregnant women & $\begin{array}{l}\text { ma zinc } \\
\text { lection time not specified }\end{array}$ & $\begin{array}{l}\text { NS mean (SD) plasma zinc in women with PE compared to women } \\
\text { with uncomplicated pregnancies. } \\
\text { PE: } 940 \text { (270) vs. uncomplicated: } 970(230) \mu g / L\end{array}$ \\
\hline \multicolumn{4}{|c|}{$\begin{array}{l}\text { a PE defined as high blood pressure }(\leq 140 / 90 \mathrm{mmHg}) \text { after } 20 \text { weeks gestation and proteinuria }(\geq 300 \mathrm{mg} / 24 \mathrm{~h}) ;{ }^{\mathrm{b}} \mathrm{GH} \text { defined as } \mathrm{l} \\
\text { gestation without proteinuria; }{ }^{\mathrm{c}} \text { PE not defined; }{ }^{\mathrm{d}} \text { Severe PE not defined; }{ }^{\mathrm{e}} \text { Mild PE defined as blood pressure } \geq 140 / 90 \text { but } 1 \\
\geq 160 / 110 \mathrm{mmHg} ;{ }^{\mathrm{f}} \mathrm{PE} \text { defined as blood pressure }>130 / 85 \text { and proteinuria } \geq 1 \text { by dipstick, severe PE defined as blood pressure }> \\
\text { by the Paris meeting of the Gestosis Organisation, } 1970 ;{ }^{\mathrm{h}} \text { PE defined as blood pressure }>130 / 85 \text { and proteinuria } \geq 1 \text { by dipst } \\
{ }^{\mathrm{i}} \text { eclampsia defined as women diagnosed with PE whom also suffer seizures that cannot be attributed to other causes. Bold pri } \\
\text { Abbreviations: AAS: atomic absorption spectrometry; GH: gestational hypertension; PE: preeclampsia; SD: standard deviation; } \\
\text { Table 3. Included studies assessing maternal zinc status and sPTB. }\end{array}$} \\
\hline Author, Country & Sample Size & $\begin{array}{l}\text { Zinc Measure } \\
\text { (1) Sample Type } \\
\text { (2) Time at Which Gestation Diet Was } \\
\text { Assessed or Sample Collected } \\
\text { (3) Method of Analysis }\end{array}$ & Outcome of the Study \\
\hline $\begin{array}{l}\text { [44] Scholl, } \\
\text { United States a }\end{array}$ & $\begin{array}{l}115 \text { with zinc intake } \leq 6 \mathrm{mg} / \text { day } \\
699 \text { with zinc intake }>6 \mathrm{mg} / \text { day }\end{array}$ & $\begin{array}{l}\text { Dietary zinc intake } \\
28 \text { and } 36 \text { weeks } \\
24 \text { h dietary recall }\end{array}$ & $\begin{array}{l}\text { 2-fold } \downarrow \text { risk of delivering a preterm infant with dietary zinc intake } \\
>6 \text { mg/day. } \\
\text { OR (LMP): } 1.85,95 \% \text { CI: } 1.09-3.12, \text { OR (OE): } 2.13 \text {, } \\
\text { 95\% CI: } 1.20-3.79 \\
2.75 \text { to } 3.44 \text {-fold } \downarrow \text { risk of delivering a very preterm infant with } \\
\text { dietary zinc intake }>9 \mathrm{mg} / \text { day. } \\
\text { OR (LMP): } 2.75,95 \% \text { Cl: } 1.31-5.77 \text {, OR (OE): } 3.44, \\
\text { 95\% Cl: } 1.39-8.55\end{array}$ \\
\hline $\begin{array}{l}\text { [94] Carmichael, } \\
\text { United States }{ }^{\mathrm{a}, \mathrm{b}}\end{array}$ & $\begin{array}{l}413 \text { preterm and } \\
58 \text { early preterm } \\
5267 \text { term }\end{array}$ & $\begin{array}{l}\text { Dietary zinc intake } \\
\text { Harvard food frequency questionnaires }\end{array}$ & $\begin{array}{l}\text { 2-fold } \downarrow \text { for preterm birth }<32 \text { weeks with zinc intake }>8.0 \mathrm{mg} / \text { day } \\
\text { compared to } 8.0-14.2 \mathrm{mg} / \text { day. } \\
\text { OR: } \mathbf{2 . 3}, \mathbf{9 5 \%} \text { CI: } \mathbf{1 . 2}-\mathbf{4 . 5}\end{array}$ \\
\hline
\end{tabular}


Table 3. Cont

\begin{tabular}{|c|c|c|c|}
\hline Author, Country & Sample Size & $\begin{array}{l}\text { Zinc Measure } \\
\text { (1) Sample Type } \\
\text { (2) Time at Which Gestation Diet Was } \\
\text { Assessed or Sample Collected } \\
\text { (3) Method of Analysis }\end{array}$ & Outcome of the Study \\
\hline $\begin{array}{l}\text { [45] Neggers, } \\
\text { United States a }\end{array}$ & $\begin{array}{l}238 \text { preterm } \\
1160 \text { term }\end{array}$ & $\begin{array}{l}\text { Dietary zinc intake } \\
18 \text { and } 30 \text { weeks } \\
24 \text { h dietary recall using the nutrient database } \\
\text { developed by the University of Minnesota }\end{array}$ & $\begin{array}{l}\text { NS association between low dietary zinc intake (less than median) } \\
\text { and risk of PTB. } \\
\text { OR: } 1.1,95 \% \text { CI: } 0.7-1.7\end{array}$ \\
\hline [95] Hsu, Taiwan ${ }^{c}$ & $\begin{array}{l}28 \text { preterm } \\
423 \text { term }\end{array}$ & $\begin{array}{l}\text { Dietary zinc intake } \\
\text { Each trimester } \\
24 \text { h dietary recall }\end{array}$ & $\begin{array}{l}\text { NS in dietary zinc intake between each of the trimesters and in } \\
\text { those who delivered preterm versus term. } \\
\text { Preterm: } 9.6-10.8 \mathrm{mg} / \text { day vs. term: } 8.90-10.9 \mathrm{mg} / \text { day }\end{array}$ \\
\hline \multicolumn{4}{|c|}{ Inadequate dietary zinc intake estimated to affect $<17 \%$ of the studied population } \\
\hline [96] Wang, China ${ }^{\text {a }}$ & $\begin{array}{l}169 \text { preterm } \\
2912 \text { uncomplicated }\end{array}$ & $\begin{array}{l}\text { Fasting serum zinc } \\
\text { First and second trimester } \\
\text { Flame AAS }\end{array}$ & $\begin{array}{l}\uparrow \text { risk of preterm birth with serum zinc }<767 \mu \mathrm{g} / \mathrm{L} \text { and serum zinc } \\
\text { between } 767 \text { and } 996 \mu \mathrm{g} / \mathrm{L} \text {. } \\
\text { aOR: } \mathbf{2 . 4 1}, \mathbf{9 5 \%} \text { CI: 1.57, 3.70; aOR: 1.97, 95\% CI: 1.27, 3.05, } \\
p<\mathbf{0 . 0 0 1} \text { for both, respectively }\end{array}$ \\
\hline [50] Bro, Denmark ${ }^{c}$ & $\begin{array}{l}34 \text { preterm } \\
220 \text { uncomplicated }\end{array}$ & $\begin{array}{l}\text { Serum zinc } \\
\text { Collected at delivery } \\
\text { Flame AAS }\end{array}$ & $\begin{array}{l}\text { NS mean (SD) serum zinc levels in women who delivered preterm } \\
\text { compared to term women. } \\
\text { Preterm: } 666.7(104.6) \text { vs. term: } 679.7(98) \mu \mathrm{g} / \mathrm{L}\end{array}$ \\
\hline $\begin{array}{l}\text { [54] Tamura, } \\
\text { United States }\end{array}$ & $\begin{array}{l}505 \text { preterm and } 136 \text { early } \\
\text { preterm } \\
2038 \text { uncomplicated }\end{array}$ & $\begin{array}{l}\text { Non-fasting heparin plasma zinc } \\
\text { Collected at first prenatal visit ( } 6 \text { to } 34 \text { weeks) } \\
\text { Flame AAS }\end{array}$ & $\begin{array}{l}\text { NS in the prevalence or } n(\%) \text { of PTB measured between the lowest } \\
\text { quartile and upper three quartiles of zinc. } \\
\text { Highest: } 373(14.5) \text { vs. lowest: } 132(15.3) \\
\text { NS in the prevalence ( } n(\%)) \text { of early PTB measured between the } \\
\text { lowest quartile and upper three quartiles of zinc. } \\
\text { Highest: } 107(4.2) \text { vs. lowest: } 29(3.4)\end{array}$ \\
\hline \multicolumn{4}{|c|}{ Inadequate dietary zinc intake estimated to affect $\geq 17 \%$ of the studied population } \\
\hline [66] Jeswani, India ${ }^{c}$ & $\begin{array}{l}25 \text { preterm } \\
25 \text { term }\end{array}$ & $\begin{array}{l}\text { Serum zinc } \\
\text { Collected at } 28-40 \text { weeks } \\
\text { AAS }\end{array}$ & $\begin{array}{l}\uparrow \text { mean (SD) serum zinc in women who delivered preterm women } \\
\text { compared to term. } \\
\text { Preterm: } \mathbf{1 1 5 4 . 4 ~ ( 1 5 4 . 1 )} \text { vs. uncomplicated: } 962.8(\mathbf{1 9 4 . 8 )} \mu \mathrm{g} / \mathrm{L} \text {, } \\
p<0.01\end{array}$ \\
\hline [64] Goel, India ${ }^{d}$ & $\begin{array}{l}20 \text { preterm } \\
25 \text { term }\end{array}$ & $\begin{array}{l}\text { Heparin plasma zinc } \\
\text { Collected at delivery } \\
\text { AAS }\end{array}$ & $\begin{array}{l}\uparrow \text { mean (SD) plasma zinc in mothers who delivered preterm } \\
\text { compared to term mothers. } \\
\text { Preterm: } 842 \text { (43) vs. term: } 744(51) \mu \mathrm{g} / \mathrm{L}, p<0.001\end{array}$ \\
\hline
\end{tabular}


Table 3. Cont.

\begin{tabular}{|c|c|c|c|}
\hline Author, Country & Sample Size & $\begin{array}{l}\text { Zinc Measure } \\
\text { (1) Sample Type } \\
\text { (2) Time at Which Gestation Diet Was } \\
\text { Assessed or Sample Collected } \\
\text { (3) Method of Analysis }\end{array}$ & Outcome of the Study \\
\hline [60] Bahl, India ${ }^{a}$ & $\begin{array}{l}10 \text { preterm } \\
97 \text { term }\end{array}$ & $\begin{array}{l}\text { Serum zinc } \\
\text { Collected at delivery } \\
\text { Flame AAS }\end{array}$ & $\begin{array}{l}\text { NS mean (SD) in women who delivered Preterm that were an } \\
\text { appropriate weight for date compared to uncomplicated. Preterm: } \\
627 \text { (212) vs. uncomplicated: } 670(96) \mu \mathrm{g} / \mathrm{L}\end{array}$ \\
\hline [65] Srivastava, India ${ }^{c}$ & $\begin{array}{l}26 \text { preterm } \\
23 \text { term }\end{array}$ & $\begin{array}{l}\text { Heparin plasma zinc } \\
\text { Collected at delivery } \\
\text { Flame AAS }\end{array}$ & $\begin{array}{l}\text { NS mean (SD) plasma zinc between preterm and term mothers. } \\
\text { Preterm: } 6350 \text { (2640) vs. term: } 6310(5090) \mu \mathrm{g} / \mathrm{L}\end{array}$ \\
\hline \multicolumn{4}{|c|}{$\begin{array}{l}{ }^{\text {a }} \text { PTB defined as }<37 \text { weeks gestation; }{ }^{b} \text { Early PTB defined as }<32 \text { weeks gestation; }{ }^{c} \text { PTB defined as } \leq 37 \text { weeks gestation; }{ }^{\text {d }} \text { PTB not defined. Bold print signifies results that were } \\
\text { significantly different. Abbreviations: AAS: atomic absorption spectrometry; aOR: adjusted odds ratio; CI: confidence interval; LMP: last menstrual period; OE: obstetric estimate; } \\
\text { PTB: preterm birth; SD: standard deviation. }\end{array}$} \\
\hline Author, Country & Sample Size & $\begin{array}{l}\text { Zinc Measure } \\
\text { (1) Sample Type } \\
\text { (2) Time at Which Gestation Diet Was } \\
\text { Assessed or Sample Collected } \\
\text { (3) Method of Analysis }\end{array}$ & Outcome of the Study \\
\hline [97] Bo, Italy a,b & $\begin{array}{l}126 \text { GDM and } 84 \text { aOGTT } \\
294 \text { uncomplicated }\end{array}$ & $\begin{array}{l}\text { Dietary zinc intake } \\
24-28 \text { weeks } \\
\text { Food frequency questionnaire }\end{array}$ & $\begin{array}{l}\downarrow \text { mean (SD) daily zinc intake between GDM and aOGTT women } \\
\text { and women with uncomplicated pregnancies. } \\
\text { GDM: } 8.5 \text { (2.4) and aOGTT: } 8.7 \text { (2.5) vs. uncomplicated: } \\
\text { 9.4 (2.8) } \mathbf{m g} \text { /day, } p=0.007\end{array}$ \\
\hline $\begin{array}{l}{[98]} \\
\text { Behboudi-Gandevani S, } \\
\text { Iran a }^{\text {a }}\end{array}$ & $\begin{array}{l}72 \text { with GDM } \\
961 \text { uncomplicated }\end{array}$ & $\begin{array}{l}\text { Dietary zinc intake } \\
14-20 \text { weeks } \\
\text { Semi-quantitative food frequency } \\
\text { questionnaire }\end{array}$ & $\begin{array}{l}\text { NS in mean (SD) daily zinc intake between GDM and those with } \\
\text { uncomplicated pregnancies. } \\
\text { GDM: } 6.91 \text { (3.42) vs. uncomplicated: } 10.1(7.45) \mathrm{mg} / \text { day }\end{array}$ \\
\hline
\end{tabular}


Table 4. Cont.

\begin{tabular}{|c|c|c|c|}
\hline Author, Country & Sample Size & $\begin{array}{l}\text { Zinc Measure } \\
\text { (1) Sample Type } \\
\text { (2) Time at Which Gestation Diet Was } \\
\text { Assessed or Sample Collected } \\
\text { (3) Method of Analysis }\end{array}$ & Outcome of the Study \\
\hline \multicolumn{4}{|c|}{ Inadequate dietary zinc intake estimated to affect $<17 \%$ of the studied population } \\
\hline [48] Borella, Italy ${ }^{\text {a }}$ & $\begin{array}{l}18 \mathrm{GDM} \\
35 \text { uncomplicated }\end{array}$ & $\begin{array}{l}\text { Heparin plasma zinc } \\
\text { Collected in the third trimester } \\
\text { Flame AAS }\end{array}$ & $\begin{array}{l}\uparrow \text { mean (SD) plasma zinc in GDM women compared to women } \\
\text { with uncomplicated pregnancies. } \\
\text { GDM: } 766.6 \text { (117.6) vs. uncomplicated: } 627.5 \text { (150) } \mu \mathrm{g} / \mathrm{L}, p<0.001\end{array}$ \\
\hline [35] Wang, China a,c & $\begin{array}{l}46 \text { GDM and } 98 \text { IGT } \\
90 \text { uncomplicated }\end{array}$ & $\begin{array}{l}\text { Plasma zinc } \\
\text { Collection time not specified } \\
\text { Inductively coupled plasma atomic emission } \\
\text { spectroscopy }\end{array}$ & $\begin{array}{l}\text { NS in mean (SD) plasma zinc between women with IGT and } \\
\text { women with uncomplicated pregnancies. } \\
\text { IGT: } 1080 \text { (270) vs. uncomplicated: } 1130 \text { (330) } \mu \text { g/L } \\
\text { NS mean (SD) plasma zinc between women with GDM and those } \\
\text { with uncomplicated pregnancies. } \\
\text { GDM:1020 (190) vs. uncomplicated: } 1130 \text { (330) } \mu \mathrm{g} / \mathrm{L}\end{array}$ \\
\hline $\begin{array}{l}\text { [38] Hyvonen-Dabek, } \\
\text { Finland }{ }^{\mathrm{d}}\end{array}$ & $\begin{array}{l}5 \mathrm{GDM} \\
10 \text { uncomplicated }\end{array}$ & $\begin{array}{l}\text { Serum zinc } \\
\text { Collection time not specified } \\
\text { Particle induced X-ray emission }\end{array}$ & $\begin{array}{l}\text { NS mean (SD) serum zinc in women with GDM compared to } \\
\text { women with uncomplicated pregnancies. } \\
\text { GDM: } 1070 \text { (190) vs. uncomplicated: } 1150(220) \mu \mathrm{g} / \mathrm{L}\end{array}$ \\
\hline [99] Wibell, Sweden d & $\begin{array}{l}20 \mathrm{GDM} \\
13 \text { uncomplicated }\end{array}$ & $\begin{array}{l}\text { Serum zinc } \\
\text { Collected across gestation } \\
\text { AAS }\end{array}$ & $\begin{array}{l}\text { NS mean (SD) serum zinc between women with GDM and those } \\
\text { with uncomplicated pregnancies. } \\
\text { GDM: } 700 \text { (100) vs. uncomplicated: } 700(80) \mu \mathrm{g} / \mathrm{L}\end{array}$ \\
\hline \multicolumn{4}{|c|}{ Inadequate dietary zinc intake estimated to affect $\geq 17 \%$ of the studied population } \\
\hline $\begin{array}{l}{[98]} \\
\text { Behboudi-Gandevani, } \\
\text { Iran }^{\text {a }}\end{array}$ & $\begin{array}{l}72 \text { with GDM } \\
961 \text { uncomplicated }\end{array}$ & $\begin{array}{l}\text { Serum zinc } \\
\text { Collected } 14-20 \text { weeks } \\
\text { Flame AAS }\end{array}$ & $\begin{array}{l}\text { NS mean serum zinc between GDM and women with } \\
\text { uncomplicated pregnancies. } \\
\text { GDM: } 844 \text { (440) vs. uncomplicated: } 835(444) \mu \mathrm{g} / \mathrm{L}\end{array}$ \\
\hline $\begin{array}{l}\text { [100] Al-Saleh, } \\
\text { Kuwait a }\end{array}$ & $\begin{array}{l}30 \mathrm{GDM} \\
30 \text { uncomplicated }\end{array}$ & $\begin{array}{l}\text { Serum zinc } \\
\text { Collected at delivery } \\
\text { Furnace AAS }\end{array}$ & $\begin{array}{l}\text { NS mean (SEM) serum zinc in women with GDM compared to } \\
\text { women with uncomplicated pregnancies. } \\
\text { GDM: } 610.3(60.1) \text { vs. uncomplicated: } 656.2(241.4) \mu \mathrm{g} / \mathrm{L}\end{array}$ \\
\hline
\end{tabular}

${ }^{a}$ GDM defined as high blood glucose levels in pregnant women who have not previously been diagnosed with diabetes which over a $3 \mathrm{~h}$ oral glucose tolerance test provided at least two values over the criteria of Carpenter and Coustan; ${ }^{b}$ aOGTT defined as high blood glucose levels in pregnant women who have not previously been diagnosed with diabetes which over a $3 \mathrm{~h}$ oral glucose tolerance test provided one abnormal value over the criteria of Carpenter and Coustan; ${ }^{\mathrm{c}}$ IGT defined as women with blood glucose consistently higher than $7.8 \mathrm{mmol} / \mathrm{L} ;{ }^{\mathrm{d}} \mathrm{GDM}$ diagnosed with an intravenous glucose tolerance test at 30 weeks gestation. Bold print signifies results that were significantly different. Abbreviations AAS: atomic absorption spectrometry; aOGTT: abnormal oral glucose tolerance test; BMI: body mass index; GDM: gestational diabetes mellitus; IGT: impaired glucose tolerance; OGTT: oral glucose tolerance test; SD: standard deviation. 
Table 5. Summary of all the studies reviewed and whether zinc status was positively, negatively or not associated with the studied pregnancy complication.

\begin{tabular}{|c|c|c|c|c|}
\hline \multicolumn{5}{|c|}{ Dietary Zinc Intake } \\
\hline $\begin{array}{l}\text { Total No. } \\
\text { Reference }\end{array}$ & LBW/SGA & Hypertensive Disorders of Pregnancy & sPTB & GDM \\
\hline 9 & $\begin{array}{l}\quad 4 \\
3 \text { reported a negative association [42-44] } \\
1 \text { reported no association [45] }\end{array}$ & $\begin{array}{c}1 \\
\text { Reported no association [70] }\end{array}$ & $\begin{array}{l}4 \\
2 \text { reported a negative association }[44,93] \\
2 \text { reported no association }[45,94]\end{array}$ & $\begin{array}{l}2 \\
1 \text { reported a negative association [96] } \\
1 \text { reported no association [97] }\end{array}$ \\
\hline \multicolumn{5}{|c|}{ Serum/Plasma Zinc } \\
\hline $\begin{array}{l}\text { Total No. } \\
\text { Reference }\end{array}$ & LBW/SGA & Hypertensive Disorders of Pregnancy & sPTB & GDM \\
\hline 58 & 26 & 33 & 7 & 6 \\
\hline \multicolumn{5}{|c|}{ No. where inadequate zinc intake affects $<17 \%$ of the population } \\
\hline & $\begin{array}{l}12 \\
2 \text { reported a negative association }[46,49] \\
2 \text { reported a positive association }[47,48] \\
8 \text { reported no association }[38,50-56]\end{array}$ & $\begin{array}{l}13 \\
5 \text { reported a negative association }[55,71-74] \\
8 \text { reported no association }[38,48,53,75-79]\end{array}$ & $\begin{array}{l}\text { 3 } \\
1 \text { reported a positive association [95] } \\
2 \text { reported no association }[50,53]\end{array}$ & $\begin{array}{l}4 \\
1 \text { reported a positive association [48] } \\
3 \text { reported no association }[35,38,98]\end{array}$ \\
\hline \multicolumn{5}{|c|}{ No. where inadequate zinc intake affects $\geq 17 \%$ of the population } \\
\hline & $\begin{array}{l}14 \\
5 \text { reported a negative association }[57-61] \\
2 \text { reported a positive association }[63,101] \\
6 \text { reported no association }[64-69]\end{array}$ & $\begin{array}{l}10 \\
10 \text { reported a negative } \\
\text { association }[33,34,36,37,39,80-83,100] \\
1 \text { reported a positive association [84] } \\
9 \text { reported no association }[32,85-92]\end{array}$ & $\begin{array}{l}4 \\
2 \text { reported a positive association }[64,66] \\
2 \text { reported no association }[60,65]\end{array}$ & $\begin{array}{c}2 \\
2 \text { reported no association }[97,99]\end{array}$ \\
\hline
\end{tabular}

Abbreviations: GDM: gestational diabetes mellitus; LBW: low birth weight; SGA: small for gestational age; sPTB: spontaneous preterm birth. 


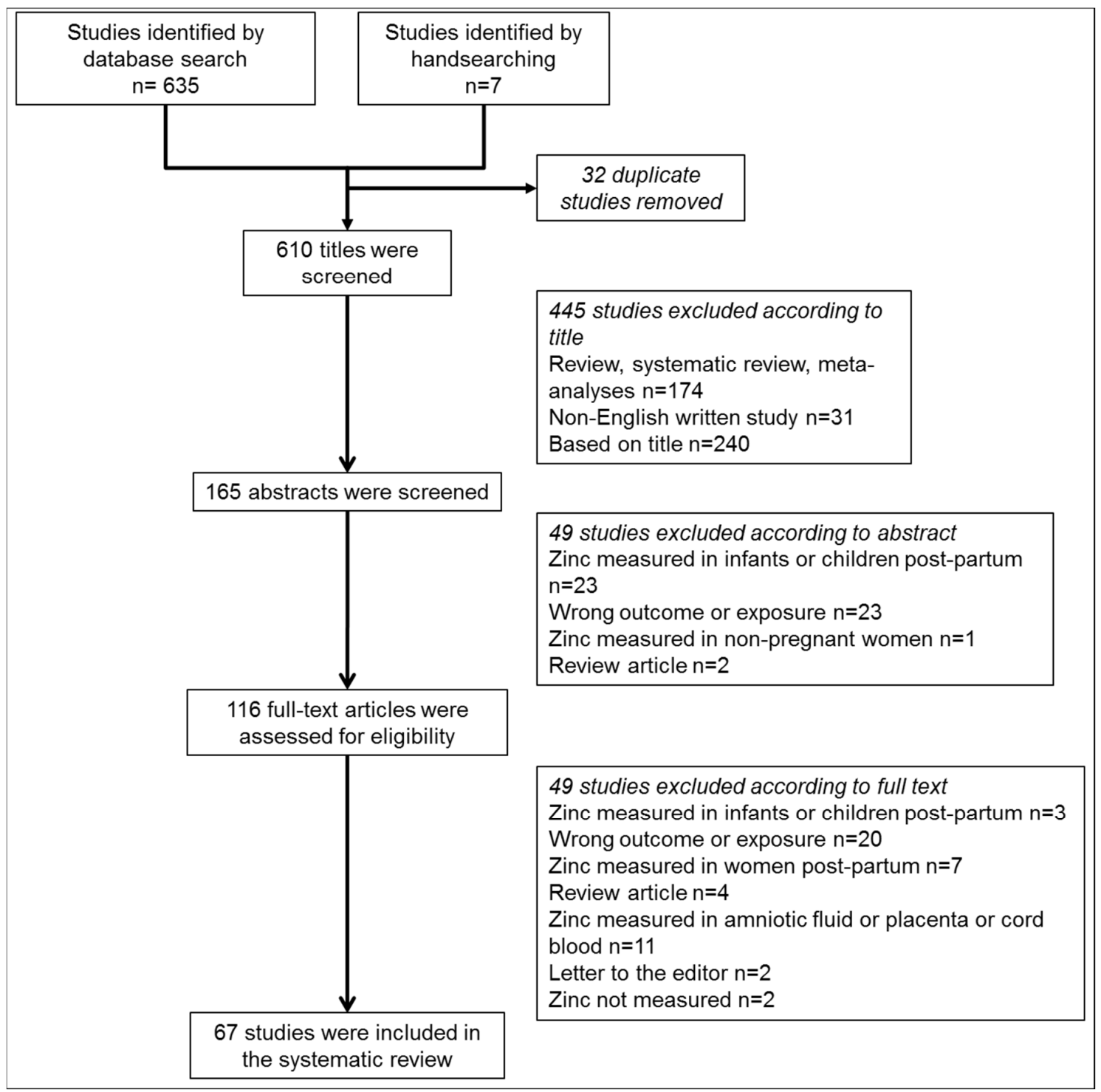

Figure 1. Flow diagram of the search strategy used in this review including the relevant number of papers at each point.

Twelve studies were identified that measured maternal circulating zinc in countries where inadequate zinc intake is predicted to be $<17 \%$, and looked at the association with birthweight (Table 1) [38,46-56]. Only one study, based on 3817 women in China, reported a 3.4-fold increase in the risk of delivering a LBW infant with serum zinc $<560 \mu \mathrm{g} / \mathrm{L}$ (adjusted RR: 3.41, 95\% CI: 1.97, 5.91) [56]. This is in contrary to two studies that reported significantly higher zinc concentrations in women with an SGA infant in the third trimester [47,55]. However, these findings were based on a relatively small number of women: 40-51 pregnant women including 10-16 women with SGA. Conversely, another study, which followed 476 women of whom 39 gave birth to an SGA infant, found the incidence of LBW to be 8 times higher in women with serum zinc in the lowest quartile (457.5-797.4 $\mu \mathrm{g} / \mathrm{L})$ compared to the highest (1039.2-1660.1 $\mu \mathrm{g} / \mathrm{L})(8.2,95 \%$ CI: 2.4-27.5) [52]. The remaining eight studies found no differences in maternal zinc concentrations between women with a SGA infant and those with an uncomplicated pregnancy. However, one study found a positive correlation between maternal zinc status and birthweight $(r=0.632, p<0.001)$ [50].

The association between maternal circulating zinc and birthweight was assessed in 14 studies based on women where inadequate dietary zinc intake was predicted to affect $\geq 17 \%$ of the 
population [57-69], of which 7 reported a significant association (Table 1) [57,59-61,66-68]. All three of the studies based on women from Africa reported serum/plasma zinc on average 72-333 $\mu \mathrm{g} / \mathrm{L}$ lower in women who gave birth to a LBW infant compared to those who gave birth to an appropriate weight infant $[57,59,67]$. In another study, the risk of delivering a LBW infant was also reported to be 3 -fold greater in women with serum zinc levels $\leq 392.2 \mu \mathrm{g} / \mathrm{L}$ compared to those with levels above this figure (3.07, 95\% CI: 1.07-8.97) [67]. Conversely, two other studies reported serum zinc to be 40-172 $\mu \mathrm{g} / \mathrm{L}$ higher in women who gave birth to a LBW infant compared to those who gave birth to an appropriate weight infant $[60,66]$. A further four studies, also based on women from India, reported no association between circulating zinc levels and birthweight $[62-64,69]$ and this was also reported in two studies of Turkish women [58,65]. However, univariate analysis and small sample size in these studies may not provide an accurate assessment of the effects of maternal circulating zinc and birthweight.

\subsection{Hypertensive Disorders of Pregnancy}

Only one study assessed dietary zinc intake and the association with hypertensive disorders (Table 4) and found no significant differences in dietary zinc intake between 13 women who developed a hypertensive disorder in pregnancy and 44 whose pregnancies remained uncomplicated [70].

Thirteen studies analyzed serum/plasma zinc in women who developed a hypertensive disorder of pregnancy in women residing in countries where inadequate zinc intake is estimated to be low $(<17 \%)$ (Table 4). Three studies reported mean serum/plasma zinc to be on average 120-1200 $\mu \mathrm{g} / \mathrm{L}$ lower in women who developed PE compared to women whose pregnancies remained uncomplicated $[49,71,72]$ and included one study that reported a reduction in risk of PE with serum levels above $1360 \mu \mathrm{g} / \mathrm{L}$ after adjusting for maternal age, height and weight before pregnancy (aOR: 0.005, 95\% CI: 0.001-0.07) [71]. A further two studies reported circulating zinc to be lower in women who developed severe PE (blood pressure $B P \geq 160 / 110$ ) compared to women whose pregnancies remained uncomplicated [73,74]. The remaining eight studies, whose sample sizes ranged from 10-271 women with PE/GH and 10-2038 women with an uncomplicated pregnancy, reported no difference in maternal zinc status between women with a hypertensive disorder of pregnancy and those without [38,47,54,75-79].

There were twenty studies that analyzed circulating zinc in women with a hypertensive disorder of pregnancy in populations where inadequate zinc intake is estimated to be $\geq 17 \%$ (Table 4) [32-34,36,37,39,80-93]. Ten studies reported mean serum/plasma zinc to be significantly lower in women who developed PE and/or GH [33,34,36,37,39,80-83,93] however, one reported plasma zinc to be higher in women with PE compared to those whose pregnancies remained uncomplicated when measured during the latent phase of labor; with (PE mean (SD): 15.53 (4.92) vs. uncomplicated: $11.93(3.11) \mu \mathrm{g} / \mathrm{g}$ protein, $p=0.003)$ [89]. These studies also included three which found circulating zinc to be $80-260 \mu \mathrm{g} / \mathrm{L}$ lower in women who developed severe PE when compared to women whose pregnancies remained uncomplicated $[37,39,83]$. A further nine studies reported no difference in circulating zinc between women with $\mathrm{PE} / \mathrm{GH}$ and those whose pregnancies remained uncomplicated.

\subsection{Spontaneous Preterm Birth}

The literature search identified four studies which measured dietary zinc intakes during pregnancy and sPTB with varying conclusions (Table 3) $[43,44,94,95]$. Two of these studies, which analyzed 5738 and 818 women respectively, determined that low zinc intake ( $\leq 6 \mathrm{mg} /$ day which is $\leq 54 \%$ of the recommended $11 \mathrm{mg} /$ day [21]) was associated with a more than 2-fold increase in the risk of delivering preterm (aOR: 2.3, 95\% CI: $1.2-4.5$ and aOR: 1.85 95\% CI: $1.09-3.12$, respectively), after adjusting for factors such as ethnicity, pre-pregnancy BMI, smoking, alcohol and multivitamin consumption [44,94]. If delivery date was calculated by last menstrual period (LMP), zinc intake below $9 \mathrm{mg} /$ day was associated with a 2.75-fold increased risk in delivering <32 weeks gestation (aOR: 2.75, 95\% CI: 1.31-5.77) [44]. However, another study reported no association between low dietary zinc intake (less than the median) and the risk of sPTB (OR: 1.1, 95\% CI: 0.7-1.7) [43] but mean zinc intake 
of the women in this study was $14 \mathrm{mg} /$ day, higher than the recommended $11 \mathrm{mg} /$ day, indicating that low zinc intake was not prevalent within this studied population.

When separated based on estimates of inadequate zinc intake, there were three studies which assessed whether there was an association between circulating zinc and SPTB in low-risk populations (Table 3). While two showed no significant difference between serum/plasma zinc levels during gestation in women who gave birth preterm and those who gave birth at term [48,54], one study which recruited 3081 women in China found a 2.4-fold increase risk of PTB with serum levels $<767 \mu \mathrm{g} / \mathrm{L}$ (aOR: 2.41, 95\% CI: 1.57, 3.70) [96].

The association between maternal circulating zinc and SPTB was determined in four studies on populations with inadequate zinc intake $\geq 17 \%$, all of which sampled women in India (Table 4) $[61,63,64,69]$. Two of the studies reported serum/plasma zinc to be higher in women who delivered preterm compared to those who delivered at term (average 98-1991 $\mu \mathrm{g} / \mathrm{L}$ increase) [63,64]. However, no difference in circulating zinc measured at delivery was reported in the remaining two studies $[61,69]$.

\subsection{Gestational Diabetes Mellitus}

Two studies looked at the association between dietary zinc intake and GDM (Table 4) [97,98]. One collected data at $24-28$ weeks gestation, and found an $11 \%$ reduction in the risk of gestational hyperglycaemia with every $1 \mathrm{mg} /$ day increase in dietary zinc intake (aOR: 0.89, 95\% CI: 0.82-0.96) [97]. The second, which sampled women at 14-20 weeks' gestation, found no association between maternal dietary zinc intakes below $50 \%$ of the recommended daily allowance and GDM (OR: 1.4, 95\% CI: 0.6-2.9) [98]. Differences between the studies included when dietary zinc was measured (early versus late second trimester) as well as ethnicity (Italian versus Iranian in which, genetic and cultural differences are likely).

Of the five studies which assessed the association between circulating zinc and GDM in countries where inadequate zinc intake is estimated to be $<17 \%$, two, both studying Italian women, reported a significant difference in serum/plasma zinc in women who developed GDM compared to women whose pregnancies remained uncomplicated (Table 4) [47,97]. However, while one study reported that serum zinc was negatively associated with the risk of hyperglycemia in pregnancy (aOR: 0.94, 95\% CI: 0.91-0.96) [97], the other found that there was in increase in serum zinc in women with GDM compared to women whose pregnancy remained uncomplicated (GDM mean (SD): 766.6 (117.6) vs. uncomplicated: 627.5 (150) $\mu \mathrm{g} / \mathrm{L}, p<0.001)$ [47]. Both studies sampled women at similar times during pregnancy and used atomic absorption spectrometry to quantitate zinc. The remaining three studies found no difference in circulating zinc $[35,38,99]$ however, given the small sample size of women with GDM in these studies $(n=5-46)$, it is likely they were underpowered and not suitable for the chosen statistical tests.

There were two studies that sampled women from countries where inadequate zinc intake was estimated to be $\geq 17 \%$ and assessed the association between maternal circulating zinc and GDM (Table 4) $[98,100]$. Neither study reported a difference in serum zinc in early pregnancy or at delivery in women with GDM compared to those whose pregnancies remained uncomplicated.

\section{Discussion}

This systematic review assessed whether maternal circulating zinc levels and/or dietary zinc intake were associated with a number of pregnancy complications. Overall, the evidence regarding the association between maternal zinc status and PE/GH, LBW/SGA, sPTB and GDM is weak and heterogeneity between the studies made comparisons difficult. However, systematic analysis of the available literature indicated some trends between maternal zinc status and infant birthweight as well as the development of severe PE (BP $\geq 160 / 110 \mathrm{mmHg}$ ).

There is consistent evidence in animal models that maternal dietary zinc deficiency during pregnancy reduces fetal growth [16-19]. From the studies that measured maternal zinc intake during 
pregnancy reviewed here, a possible relationship between low zinc intake $(\leq 54 \%$ of the recommended $11 \mathrm{mg} /$ day) and decreased infant birthweight may exist in human populations. Both food frequency questionnaires and $24 \mathrm{~h}$ recalls are limited by the preparedness of the participants to accurately record their diets, the food composition tables used and their ability to capture variations within diets [102]. This may explain the conflicting results between studies which assessed dietary zinc intake and the association with infant birthweight, sPTB and GDM. However, three of the four studies that measured dietary zinc intake in pregnancy and recorded infant birthweight reported a significant reduction in maternal zinc status in those who delivered a LBW/SGA infant $[42,44,45]$. The relationship between infant birthweight and maternal serum/plasma zinc is less clear. Plasma measures of zinc are considered preferable over serum as erythrocytes can be a source of zinc contamination within serum samples [22]. However, plasma zinc only accounts for approximately $0.1 \%$ of total body zinc [103], is heavily influenced by confounding factors like stress, infection and hormones [101,104-107] and does not directly correlate with dietary zinc intake [108]. This limits how useful measuring circulating zinc is as a biomarker for health and disease. When studies on LBW/SGA that measured maternal circulating zinc were separated based on populations where inadequate zinc intake is predicted to be $\geq 17 \%, 7$ of the 13 studies reported a difference in serum/plasma zinc between women who delivered LBW/SGA infant and those whose infants were of an appropriate weight. Given the lack of suitable alternatives, particularly in studies of pregnant women, determining zinc status by measuring serum/plasma zinc can still be informative about the importance of zinc to pregnancy, especially if measured in conjunction with dietary zinc intakes.

Other maternal factors such as age, BMI, smoking status and alcohol consumption in pregnancy not only influence pregnancy outcome but also circulating zinc [109,110]. BMI is a significant factor in influencing the risk for developing PE and GH [111,112]. However, only 11 of the 32 studies on PE/GH $[33,36,54,71,75,79,80,82,84,88,92]$ reported on BMI, making it difficult to comment on whether differences in BMI may be influencing the outcomes of the studies included in this review. Despite this, there may be a relationship between maternal circulating zinc levels and the severity of PE. Mean maternal zinc concentrations in women with severe PE (ranging from 388 to $410 \mu \mathrm{g} / \mathrm{L}$ ) [73,74,83] were well below $562.1 \mu \mathrm{g} / \mathrm{L}$, which is the defined zinc deficiency cut-off [26,113]. In women with mild PE and those with uncomplicated pregnancies, mean maternal zinc concentrations ranged between 684-831 $\mu \mathrm{g} / \mathrm{L}[37,39,83]$ and 630-1022 $\mu \mathrm{g} / \mathrm{L}[37,39,74,83]$ respectively. A current leading hypothesis relating to the development of PE is increased placental oxidative stress [114]. Zinc itself has antioxidant capabilities and is an integral structural component of superoxide dismutase, a first line defense antioxidant [115] which has reduced activity in cell lines, animal models and human studies of zinc deficiency [116-120]. Hence, it is possible in pregnancies complicated by PE, that low maternal zinc concentration $(<562.1 \mu \mathrm{g} / \mathrm{L})$ may reduce the potential to combat rises in free radical production and increase the severity of the complication.

Zinc levels in maternal circulation decrease across gestation; this is thought to be due to a combination of increased maternal blood volume and fetal demands [40,121-123], and therefore comparisons between studies which measured zinc in maternal serum or plasma early in pregnancy versus late should be interpreted with caution. Overall, regardless of pregnancy outcome, the majority (31 out of 59 studies which measured maternal circulating zinc) collected samples during labor or at delivery. Physiologically, parturition results in huge changes to maternal hormonal profile with rises in estrogen, oxytocin and prostaglandin required to initiate labor [124]. Furthermore, there is an increase in the production of inflammatory cytokines and a withdrawal of anti-inflammatory cytokines within the gestational tissues [125]. Infection and inflammation decrease plasma zinc [104] and use of the contraceptive pill, which raises estrogen and progesterone levels, also decreases circulating zinc $[101,105]$. Given that pregnancy itself is likely to confound zinc status, this has implications for interpreting studies that have measured serum/plasma zinc at delivery. In addition, how zinc may be associated with a pregnancy outcome needs to be measured before the pregnancy complication has manifested. Only five studies of 6795 pregnant women in total measured either circulating zinc or 
dietary zinc intake prior to 20 weeks gestation $[44,53,54,79,98]$. All found no significant difference in maternal zinc status during this time period between women who developed a pregnancy complication and those who did not, indicating that zinc status in early pregnancy may not be associated with adverse pregnancy outcomes.

Due to the additional demands associated with pregnancy and fetal growth, pregnant women are more vulnerable to multiple nutrient deficiencies [126] and this is potentially another cofounding factor when assessing the association between maternal zinc status and pregnancy outcome. This is because nutrients can interact with each other in both a positive (e.g., vitamin A and zinc [127]) and negative manner (e.g., calcium or iron and zinc [128,129]). A number of studies reviewed here measured serum/plasma concentrations of other nutrients as well as zinc, including copper [35,97], iron [75,98], selenium [51,88], magnesium [95,99] and lead [78]. While circulating zinc levels were not different for the pregnancy outcomes studied in these articles, those of other micronutrients were. Serum copper concentrations were found to be higher in women with GDM or those who delivered an SGA infant when compared to women with an uncomplicated pregnancy in two studies [35,97]. Furthermore, serum iron was higher in women with PE and GDM compared to women whose pregnancies were uncomplicated [75,98]. Two other studies found selenium to be lower in the serum of women with PE or those who delivered an SGA infant compared to women with an uncomplicated pregnancy $[51,88]$. Therefore, it is important to consider other nutritional factors that may influence pregnancy outcome as well as micronutrient ratios in order to fully understand the importance of micronutrient status on pregnancy success.

Finally, the lack of studies identified in this review analyzing truly zinc deficient women, nor those in populations at high risk of zinc deficiency, is a major limitation in determining the effects of zinc on pregnancy outcome. Only 8 of the 64 studies reported mean circulating zinc below $562.1 \mu \mathrm{g} / \mathrm{L}[49,50,60,72,74,83,87,91]$ and there were very few studies based on women in countries where inadequate zinc intake is predicted to be prevalent like South-East Asia and parts of Africa [26,27]. The majority of studies were based on populations in the United States and Europe where zinc deficiency is estimated to only affect $3.9 \%-12.7 \%$ of the population [26]. Therefore, there is the potential that the results from this review may be skewed given the lack of evidence based on women living in areas predicted to be at high risk of zinc deficiency.

\section{Conclusions}

The current review has explored the connection between maternal zinc status and pregnancy complications including hypertensive disorders of pregnancy, infant birthweight, spontaneous preterm birth (sPTB) and gestational diabetes mellitus (GDM). While it appears that there may be a relationship between maternal dietary zinc intake and infant birthweight and the development of severe PE, there is little evidence to suggest an association between zinc and SPTB or GDM. However, heterogeneity in the studies identified in this review reflects real uncertainty in the evidence linking zinc deficiency and pregnancy complications and therefore this warrants further study, particularly in developing countries whose populations are at increased risk of zinc deficiency. If we are to continue to reduce preventable deaths of newborns and children under the age of five [6], understanding the importance of micronutrients like zinc in child development, particularly in utero, will greatly increase the likelihood of success. Future studies need to focus on women more vulnerable to zinc deficiency in pregnancy in order to fully determine the effects of zinc status on pregnancy outcome.

Acknowledgments: This project was funded in part by a National Health and Medical Research Council of Australia (NHMRC) Project Grant (GNT1020754) awarded to CTR. CTR is supported by a NHMRC Senior Research Fellowship GNT1020749. RLW is supported by an Australian Postgraduate Award.

Author Contributions: All authors contributed to conceiving and designing the systematic review. R.L.W. performed the literature search and along with J.A.G. read and compiled the results. R.L.W. wrote the paper and J.A.G., T.B.M. and C.T.R. edited the final manuscript.

Conflicts of Interest: The authors declare no conflict of interest. 


\section{Appendix A}

Outline of the search terms and MeSH headings identified in the Medline search and used for the remaining database searches.

Search strategy: MEDLINE (OVID).

\begin{tabular}{clc}
\hline & Searches & Results \\
\hline 1 & exp Zinc/ or zinc.mp. & 108,695 \\
2 & plasma zinc.mp. & 1365 \\
3 & zinc intake.mp. & 679 \\
4 & dietary zinc.mp. & 1158 \\
5 & serum zinc.mp. & 2083 \\
6 & 1 or 2 or 3 or 4 or 5 & 108,695 \\
7 & preterm birth.mp. or exp Premature Birth/ & 14,642 \\
8 & premature birth.mp. or Premature Birth/ & 11,131 \\
9 & small for gestational age.mp. & 9255 \\
10 & exp Infant, Small for Gestational Age/ & 5977 \\
11 & gestational hypertension.mp. or exp Hypertension, Pregnancy-Induced/ & 32,078 \\
12 & pre?eclampsia.mp. or exp Pre-Eclampsia/ & 30,863 \\
13 & exp Pre-Eclampsia/ or exp Eclampsia/ or eclampsia.mp. & 32,471 \\
14 & exp HELLP Syndrome/ or HELPP syndrome.mp. & 1613 \\
15 & gestational diabetes.mp. or exp Diabetes, Gestational/ & 11,382 \\
16 & fetal macrosomia.mp. or exp Fetal Macrosomia/ & 2369 \\
17 & 7 or 8 or 9 or 10 or 11 or 12 or 13 or 14 or 15 or 16 & 69,148 \\
18 & infant, low birth weight.mp. or Infant, Low Birth Weight/ & 16,571 \\
19 & infant, very low birth weight.mp. or exp Infant, Very Low Birth Weight/ & 8491 \\
20 & 17 or 18 or 19 & 89,771 \\
21 & 6 and 20 & 380 \\
22 & limit 21 to (english language and full text and humans) & 165 \\
\hline
\end{tabular}

\section{Appendix B}

List of conversion factors used to convert all measures of zinc to $\mu \mathrm{g} / \mathrm{L}$.

\begin{tabular}{cc}
\hline Units & Conversion \\
\hline$\mu \mathrm{g} / 100 \mathrm{~mL}$ or $\mu \mathrm{g} / \mathrm{dL}$ & Multiply 10 \\
$\mu \mathrm{mol} / \mathrm{L}$ or $\mu \mathrm{M}$ & Divide 0.153 \\
$\mathrm{mg} / \mathrm{L}$ & Multiply 1000 \\
$\mu \mathrm{g} / \mathrm{mL}$ & Multiply 1000 \\
\hline
\end{tabular}

\section{References}

1. Black, R.E.; Victora, C.G.; Walker, S.P.; Bhutta, Z.A.; Christian, P.; de Onis, M.; Ezzati, M.; Grantham-McGregor, S.; Katz, J.; Martorell, R.; et al. Maternal and child undernutrition and overweight in low-income and middle-income countries. Lancet 2013, 382, 427-451. [CrossRef]

2. Grieger, J.A.; Clifton, V.L. A review of the impact of dietary intakes in human pregnancy on infant birthweight. Nutrients 2015, 7, 153-178. [CrossRef] [PubMed]

3. Gluckman, P.D.; Hanson, M.A. Developmental origins of disease paradigm: A mechanistic and evolutionary perspective. Pediatr. Res. 2004, 56, 311-317. [CrossRef] [PubMed]

4. Black, R.E.; Allen, L.H.; Bhutta, Z.A.; Caulfield, L.E.; de Onis, M.; Ezzati, M.; Mathers, C.; Rivera, J. Maternal and child undernutrition: Global and regional exposures and health consequences. Lancet 2008, 371, 243-260. [CrossRef]

5. Fischer Walker, C.L.; Ezzati, M.; Black, R.E. Global and regional child mortality and burden of disease attributable to zinc deficiency. Eur. J. Clin. Nutr. 2009, 63, 591-597. [CrossRef] [PubMed]

6. Organisation WH (2015) Fact Sheet No 290-Millennium Development Goals (MDGs). Available online: http:/ / www.who.int/mediacentre/factsheets/fs290/en/\# (accessed on 13 January 2016). 
7. Cousins, R.; Zinc, I.; Bowman, B.A.; Russell, R.M. Present Knowledge in Nutrition; DC ILSI Press: Washington, DC, USA, 2006; Volume 9, pp. 445-457.

8. MacDonald, R.S. The role of zinc in growth and cell proliferation. J. Nutr. 2000, 130, 1500s-1508s. [PubMed]

9. Maret, W. Molecular aspects of human cellular zinc homeostasis: Redox control of zinc potentials and zinc signals. Biometals 2009, 22, 149-157. [CrossRef] [PubMed]

10. Prasad, A.S. Clinical, immunological, anti-inflammatory and antioxidant roles of zinc. Exp. Gerontol. 2008, 43, 370-377. [CrossRef] [PubMed]

11. Butler Walker, J.; Houseman, J.; Seddon, L.; McMullen, E.; Tofflemire, K.; Mills, C.; Corriveau, A.; Weber, J.-P.; LeBlanc, A.; Walker, M. Maternal and umbilical cord blood levels of mercury, lead, cadmium, and essential trace elements in Arctic Canada. Environ. Res. 2006, 100, 295-318. [CrossRef] [PubMed]

12. Perveen, S.; Altaf, W.; Vohra, N.; Bautista, M.L.; Harper, R.G.; Wapnir, R.A. Effect of gestational age on cord blood plasma copper, zinc, magnesium and albumin. Early Hum. Dev. 2002, 69, 15-23. [CrossRef]

13. Tsuzuki, S.; Morimoto, N.; Hosokawa, S.; Matsushita, T. Associations of maternal and neonatal serum trace element concentrations with neonatal birth weight. PLoS ONE 2013, 8, e75627. [CrossRef] [PubMed]

14. Swanson, C.A.; King, J.C. Reduced serum zinc concentration during pregnancy. Obstet. Gynecol. 1983, 62, 313-318. [CrossRef] [PubMed]

15. Hurley, L.S.; Swenerton, H. Congenital malformations resulting from zinc deficiency in rats. Proc. Soc. Exp. Biol. Med. 1966, 123, 692-696. [CrossRef] [PubMed]

16. Dempsey, C.; McCormick, N.H.; Croxford, T.P.; Seo, Y.A.; Grider, A.; Kelleher, S.L. Marginal maternal zinc deficiency in lactating mice reduces secretory capacity and alters milk composition. J. Nutr. 2012, 142, 655-660. [CrossRef] [PubMed]

17. Kim, J.T.; Baek, S.H.; Lee, S.H.; Park, E.K.; Kim, E.C.; Kwun, I.S.; Shin, H.I. Zinc-deficient diet decreases fetal long bone growth through decreased bone matrix formation in mice. J. Med. Food 2009, 12, 118-123. [CrossRef] [PubMed]

18. McCormick, N.H.; King, J.; Krebs, N.; Soybel, D.I.; Kelleher, S.L. Redistribution of tissue zinc pools during lactation and dyshomeostasis during marginal zinc deficiency in mice. J. Trace Elem. Med. Biol. 2014, 29, 170-175. [CrossRef] [PubMed]

19. Tian, X.; Anthony, K.; Neuberger, T.; Diaz, F.J. Preconception zinc deficiency disrupts postimplantation fetal and placental development in mice. Biol. Reprod. 2014, 90, 83. [CrossRef] [PubMed]

20. Brown, K.H.; Wuehler, S.E.; Peerson, J.M. The importance of zinc in human nutrition and estimation of the global prevalence of zinc deficiency. Food Nutr. Bull. 2001, 22, 113-125. [CrossRef]

21. National Health and Medical Research Council. Nutrient Reference Values for Australia and New Zealand; NHMRC: Canberra, Australia, 2005.

22. Food and Nutrition Board: Institute of Medicine. Dietary Reference Intakes for Vitamin A, Vitamin K, Arsenic, Boron, Chromium, Copper, Iodine, Iron, Manganese, Molybdenum, Nickel, Silicon, Vanadium, and Zinc; The National Academies Press: Washington, DC, USA, 2001.

23. Caulfield, L.E.; Zavaleta, N.; Shankar, A.H.; Merialdi, M. Potential contribution of maternal zinc supplementation during pregnancy to maternal and child survival. Am. J. Clin. Nutr. 1998, 68, 499s-508s. [PubMed]

24. King, J.C. Determinants of maternal zinc status during pregnancy. Am. J. Clin. Nutr. 2000, 71, 1334s-1343s. [PubMed]

25. Parr, R. Assessment of dietary intakes. Trace Elem. Hum. Nutr. Health 1996, 1996, 265-288.

26. Caulfield, L.E.; Black, R.E. Zinc deficiency. In Comparative Quantification of Health Risks: Global and Regional Burden of Disease Attributable to Selected Major Risk Factors Geneva; World Health Organization: Geneva, Swizterland, 2004; pp. 257-279.

27. Wessells, K.R.; Brown, K.H. Estimating the global prevalence of zinc deficiency: Results based on zinc availability in national food supplies and the prevalence of stunting. PLoS ONE 2012, 7, e50568. [CrossRef] [PubMed]

28. Ota, E.; Mori, R.; Middleton, P.; Tobe-Gai, R.; Mahomed, K.; Miyazaki, C.; Bhutta, Z.A. Zinc supplementation for improving pregnancy and infant outcome. Cochrane Database Syst. Rev. 2015. [CrossRef]

29. Shah, D.; Sachdev, H.P. Effect of gestational zinc deficiency on pregnancy outcomes: Summary of observation studies and zinc supplementation trials. Br. J. Nutr. 2001, 85, S101-S108. [CrossRef] [PubMed] 
30. Ma, Y.; Shen, X.; Zhang, D. The relationship between serum zinc level and preeclampsia: A Meta-Analysis. Nutrients 2015, 7, 7806-7820. [CrossRef] [PubMed]

31. Liberati, A.; Altman, D.G.; Tetzlaff, J.; Mulrow, C.; Gotzsche, P.C.; Ioannidis, J.P.; Clarke, M.; Devereaux, P.J.; Kleijnen, J.; Moher, D. The PRISMA statement for reporting systematic reviews and meta-analyses of studies that evaluate health care interventions: Explanation and elaboration. J. Clin. Epidemiol. 2009, 62, e1-e34. [CrossRef] [PubMed]

32. Adeniyi, F.A. The implications of hypozincemia in pregnancy. Acta Obstet. Gynecol. Scand. 1987, 66, 579-582. [CrossRef] [PubMed]

33. Akinloye, O.; Oyewale, O.J.; Oguntibeju, O.O. Evaluation of trace elements in pregnant women with pre-eclampsia. Afr. J. Biotechnol. 2010, 9, 5196-5202.

34. Kumru, S.; Aydin, S.; Simsek, M.; Sahin, K.; Yaman, M.; Ay, G. Comparison of serum copper, zinc, calcium, and magnesium levels in preeclamptic and healthy pregnant women. Biol. Trace Elem. Res. 2003, 94, 105-112. [CrossRef]

35. Wang, Y.; Tan, M.; Huang, Z.; Sheng, L.; Ge, Y.; Zhang, H.; Jiang, M.; Zhang, G. Elemental contents in serum of pregnant women with gestational diabetes mellitus. Biol. Trace Elem. Res. 2002, 88, 113-118. [CrossRef]

36. Farzin, L.; Sajadi, F. Comparison of serum trace element levels in patients with or without pre-eclampsia. J. Res. Med. Sci. 2012, 17, 938-941. [PubMed]

37. Gupta, S.; Jain, N.P.; Avasthi, K.; Wander, G.S. Plasma and erythrocyte zinc in pre-eclampsia and its correlation with foetal outcome. J. Assoc. Phys. India 2014, 62, 306-310.

38. Hyvonen-Dabek, M.; Nikkinen-Vilkki, P.; Dabek, J.T. Selenium and other elements in human maternal and umbilical serum, as determined simultaneously by proton-induced X-ray emission. Clin. Chem. 1984, 30, 529-533. [PubMed]

39. Jain, S.; Sharma, P.; Kulshreshtha, S.; Mohan, G.; Singh, S. The role of calcium, magnesium, and zinc in pre-eclampsia. Biol. Trace Elem. Res. 2010, 133, 162-170. [CrossRef] [PubMed]

40. Donangelo, C.M.; King, J.C. Maternal zinc intakes and homeostatic adjustments during pregnancy and lactation. Nutrients 2012, 4, 782-798. [CrossRef] [PubMed]

41. Tamura, T.; Goldenberg, R.L. Zinc nutriture and pregnancy outcome. Nutr. Res. 1996, 16, 139-181. [CrossRef]

42. Simmer, K.; Iles, C.A.; Slavin, B.; Keeling, P.W.; Thompson, R.P. Maternal nutrition and intrauterine growth retardation. Hum. Nutr. Clin. Nutr. 1987, 41, 193-197. [PubMed]

43. Negandhi, P.H.; Negandhi, H.N.; Zodpey, S.P.; Ughade, S.N.; Biranjan, J.R. Risk factors for low birth weight in an Indian urban setting: A nested case control study. Asia Pac. J. Public Health 2014, 26, 461-469. [CrossRef] [PubMed]

44. Scholl, T.O.; Hediger, M.L.; Schall, J.I.; Fischer, R.L.; Khoo, C.S. Low zinc intake during pregnancy: Its association with preterm and very preterm delivery. Am. J. Epidemiol. 1993, 137, 1115-1124. [PubMed]

45. Neggers, Y.H.; Goldenberg, R.L.; Tamura, T.; Cliver, S.P.; Hoffman, H.J. The relationship between maternal dietary intake and infant birthweight. Acta Obstet. Gynecol. Scand. Suppl. 1997, 165, 71-75. [PubMed]

46. Wang, H.; Hu, Y.-F.; Hao, J.-H.; Chen, Y.-H.; Su, P.-Y.; Wang, Y.; Yu, Z.; Fu, L.; Xu, Y.-Y.; Zhang, C.; et al. Maternal zinc deficiency during pregnancy elevates the risks of fetal growth restriction: A population-based birth cohort study. Sci. Rep. 2015, 5, 11262. [CrossRef] [PubMed]

47. Voss Jepsen, L.; Clemmensen, K. Zinc in Danish women during late normal pregnancy and pregnancies with intra-uterine growth retardation. Acta Obstet. Gynecol. Scand. 1987, 66, 401-405. [CrossRef] [PubMed]

48. Borella, P.; Szilagyi, A.; Than, G.; Csaba, I.; Giardino, A.; Facchinetti, F. Maternal plasma concentrations of magnesium, calcium, zinc and copper in normal and pathological pregnancies. Sci. Total Environ. 1990, 99, 67-76. [CrossRef]

49. Neggers, Y.H.; Cutter, G.R.; Acton, R.T.; Alvarez, J.O.; Bonner, J.L.; Goldenberg, R.L.; Go, R.C.; Roseman, J.M. A positive association between maternal serum zinc concentration and birth weight. Am. J. Clin. Nutr. 1990, 51, 678-684. [PubMed]

50. Bro, S.; Berendtsen, H.; Norgaard, J.; Host, A.; Jorgensen, P.J. Serum zinc and copper concentrations in maternal and umbilical cord blood. Relation to course and outcome of pregnancy. Scand. J. Clin. Lab. Investig. 1988, 48, 805-811. [CrossRef]

51. Mistry, H.D.; Kurlak, L.O.; Young, S.D.; Briley, A.L.; Pipkin, F.B.; Baker, P.N.; Poston, L. Maternal selenium, copper and zinc concentrations in pregnancy associated with small-for-gestational-age infants. Matern. Child. Nutr. 2014, 10, 327-334. [CrossRef] [PubMed] 
52. Tamura, T.; Goldenberg, R.L.; Johnston, K.E.; Cliver, S.P.; Hoffman, H.J. Serum concentrations of zinc, folate, vitamins $\mathrm{A}$ and $\mathrm{E}$, and proteins, and their relationships to pregnancy outcome. Acta Obstet. Gynecol. Scand. Suppl. 1997, 165, 63-70. [PubMed]

53. Tamura, T.; Goldenberg, R.L.; Johnston, K.E.; DuBard, M. Maternal plasma zinc concentrations and pregnancy outcome. Am. J. Clin. Nutr. 2000, 71, 109-113. [PubMed]

54. Ghosh, A.; Fong, L.Y.; Wan, C.W.; Liang, S.T.; Woo, J.S.; Wong, V. Zinc deficiency is not a cause for abortion, congenital abnormality and small-for-gestational age infant in Chinese women. Br. J. Obstet. Gynaecol. 1985, 92, 886-891. [CrossRef] [PubMed]

55. Cherry, F.F.; Bennett, E.A.; Bazzano, G.S.; Johnson, L.K.; Fosmire, G.J.; Batson, H.K. Plasma zinc in hypertension/toxemia and other reproductive variables in adolescent pregnancy. Am. J. Clin. Nutr. 1981, 34, 2367-2375. [PubMed]

56. Bogden, J.D.; Thind, I.S.; Kemp, F.W.; Caterini, H. Plasma concentrations of calcium, chromium, copper, iron, magnesium, and zinc in maternal and cord blood and their relationship to low birth weight. J. Lab. Clin. Med. 1978, 92, 455-462. [PubMed]

57. Atinmo, T.; Mbofung, C.; Osinusi, B.O. Relationship of zinc and copper concentrations in maternal and cord blood and birth weight. Int. J. Gynaecol. Obstet. 1980, 18, 452-454. [PubMed]

58. Abass, R.M.; Hamdan, H.Z.; Elhassan, E.M.; Hamdan, S.Z.; Ali, N.I.; Adam, I. Zinc and copper levels in low birth weight deliveries in Medani Hospital, Sudan. BMC Res. Notes 2014, 7, 386. [CrossRef] [PubMed]

59. Rwebembera, A.A.-B.; Munubhi, E.K.D.; Manji, K.P.; Mpembeni, R.; Philip, J. Relationship between infant birth weight $</=2000 \mathrm{~g}$ and maternal zinc levels at Muhimbili National Hospital, Dar Es Salaam, Tanzania. J. Trop. Pediatr. 2006, 52, 118-125. [PubMed]

60. Bahl, L.; Chaudhuri, L.S.; Pathak, R.M. Study of serum zinc in neonates and their mothers in Shimla hills (Himachal Pradesh). Indian J. Pediatr. 1994, 61, 571-575. [CrossRef] [PubMed]

61. Singh, P.P.; Khushlani, K.; Veerwal, P.C.; Gupta, R.C. Relationship between birth weight and zinc status of newly born infants and their mothers. Indian J. Physiol. Pharmacol. 1989, 33, 134-135. [PubMed]

62. Prema, K. Predictive value of serum copper and zinc in normal and abnormal pregnancy. Indian J. Med. Res. 1980, 71, 554-560. [PubMed]

63. Badakhsh, M.H.; Khamseh, M.E.; Seifoddin, M.; Kashanian, M.; Malek, M.; Shafiee, G.; Baradaran, H.R. Impact of maternal zinc status on fetal growth in an Iranian pregnant population. Gynecol. Endocrinol. 2011, 27, 1074-1076. [CrossRef] [PubMed]

64. Goel, R.; Misra, P.K. Study of plasma zinc in neonates and their mothers. Indian Pediatr. 1982, 19, 611-614. [PubMed]

65. Srivastava, S.; Mehrotra, P.K.; Srivastava, S.P.; Siddiqui, M.K.J. Some essential elements in maternal and cord blood in relation to birth weight and gestational age of the baby. Biol. Trace Elem. Res. 2002, 86, 97-105. [PubMed]

66. Jeswani, R.M.; Vani, S.N. A study of serum zinc levels in cord blood of neonates and their mothers. Indian J. Pediatr. 1991, 58, 683-686. [CrossRef] [PubMed]

67. George, S.S.; Swaminathan, S.; Kanagasabapathy, A.S.; Seshadri, L. Maternal zinc indices and small babies. Natl. Med. J. India 1998, 11, 120-121. [PubMed]

68. Akman, I.; Arioglu, P.; Koroglu, O.A.; Sakalli, M.; Ozek, E.; Topuzoglu, A.; Eren, S.; Bereket, A. Maternal zinc and cord blood zinc, insulin-like growth factor-1, and insulin-like growth factor binding protein-3 levels in small-for-gestational-age newborns. Clin. Exp. Obstet. Gynecol. 2006, 33, 238-240. [PubMed]

69. Ozdemir, U.; Gulturk, S.; Aker, A.; Guvenal, T.; Imir, G.; Erselcan, T. Correlation between birth weight, leptin, zinc and copper levels in maternal and cord blood. J. Physiol. Biochem. 2007, 63, 121-128. [CrossRef] [PubMed]

70. Tande, D.L.; Ralph, J.L.; Johnson, L.K.; Scheett, A.J.; Hoverson, B.S.; Anderson, C.M. First trimester dietary intake, biochemical measures, and subsequent gestational hypertension among nulliparous women. J. Midwifery Womens Health 2013, 58, 423-430. [CrossRef] [PubMed]

71. Lazebnik, N.; Kuhnert, B.R.; Kuhnert, P.M. Zinc, cadmium, and hypertension in parturient women. Am. J. Obstet. Gynecol. 1989, 161, 437-440. [CrossRef]

72. Kim, J.; Kim, Y.J.; Lee, R.; Moon, J.H.; Jo, I. Serum levels of zinc, calcium, and iron are associated with the risk of preeclampsia in pregnant women. Nutr. Res. 2012, 32, 764-769. [CrossRef] [PubMed] 
73. Kiilholma, P.; Paul, R.; Pakarinen, P.; Gronroos, M. Copper and zinc in pre-eclampsia. Acta Obstet. Gynecol. Scand. 1984, 63, 629-631. [CrossRef] [PubMed]

74. Araujo Brito, J.; do Nascimento Marreiro, D.; Moita Neto, J.M.; Michelle Costa e Silva, D.; Goncalves de Sousa Almondes, K.; Valadares Neto, J.D.D.; do Nascimento Nogueira, N. Enzyme activity of superoxide dismutase and zincemia in women with preeclampsia. Nutr. Hosp. 2013, 28, 486-490. [PubMed]

75. Magri, J.; Sammut, M.; Savona-Ventura, C. Lead and other metals in gestational hypertension. Int. J. Gynaecol. Obstet. 2003, 83, 29-36. [CrossRef]

76. Fenzl, V.; Flegar-Mestric, Z.; Perkov, S.; Andrisic, L.; Tatzber, F.; Zarkovic, N.; Duic, Z. Trace elements and oxidative stress in hypertensive disorders of pregnancy. Arch. Gynecol. Obstet. 2013, 287, 19-24. [CrossRef] [PubMed]

77. Katz, O.; Paz-Tal, O.; Lazer, T.; Aricha-Tamir, B.; Mazor, M.; Wiznitzer, A.; Sheiner, E. Severe pre-eclampsia is associated with abnormal trace elements concentrations in maternal and fetal blood. J. Matern. Fetal Neonatal Med. 2012, 25, 1127-1130. [CrossRef] [PubMed]

78. Mistry, H.D.; Gill, C.A.; Kurlak, L.O.; Seed, P.T.; Hesketh, J.E.; Meplan, C.; Schomburg, L.; Chappell, L.C.; Morgan, L.; Poston, L. Association between maternal micronutrient status, oxidative stress, and common genetic variants in antioxidant enzymes at 15 weeks gestation in nulliparous women who subsequently develop preeclampsia. Free Radic. Biol. Med. 2015, 78, 147-155. [CrossRef] [PubMed]

79. Lao, T.T.; Chin, R.K.; Swaminathan, R.; Mak, Y.T. Plasma and erythrocyte zinc concentrations in pre-eclampsia. Eur. J. Obstet. Gynecol. Reprod. Biol. 1989, 30, 117-122. [CrossRef]

80. Sarwar, M.S.; Ahmed, S.; Ullah, M.S.; Kabir, H.; Rahman, G.K.M.M.; Hasnat, A.; Islam, M.S. Comparative study of serum zinc, copper, manganese, and iron in preeclamptic pregnant women. Biol. Trace Elem. Res. 2013, 154, 14-20. [CrossRef] [PubMed]

81. Ilhan, N.; Ilhan, N.; Simsek, M. The changes of trace elements, malondialdehyde levels and superoxide dismutase activities in pregnancy with or without preeclampsia. Clin. Biochem. 2002, 35, 393-397. [CrossRef]

82. Bakacak, M.; Kilinc, M.; Serin, S.; Ercan, O.; Kostu, B.; Avci, F.; Kiran, H.; Kiran, G. Changes in copper, zinc, and malondialdehyde levels and superoxide dismutase activities in pre-eclamptic pregnancies. Med. Sci. Monit. 2015, 21, 2414-2420. [PubMed]

83. Al-Jameil, N.; Tabassum, H.; Al-Mayouf, H.; Aljohar, H.I.; Alenzi, N.D.; Hijazy, S.M.; Khan, F.A. Analysis of serum trace elements-copper, manganese and zinc in preeclamptic pregnant women by inductively coupled plasma optical emission spectrometry: A prospective case controlled study in Riyadh, Saudi Arabia. Int. J. Clin. Exp. Pathol. 2014, 7, 1900-1910. [PubMed]

84. Bassiouni, B.A.; Foda, A.I.; Rafei, A.A. Maternal and fetal plasma zinc in pre-eclampsia. Eur. J. Obstet. Gynecol. Reprod. Biol. 1979, 9, 75-80. [CrossRef]

85. Harma, M.; Harma, M.; Kocyigit, A. Correlation between maternal plasma homocysteine and zinc levels in preeclamptic women. Biol. Trace Elem. Res. 2005, 104, 97-105. [CrossRef]

86. Rafeeinia, A.; Tabandeh, A.; Khajeniazi, S.; Marjani, A.J. Serum copper, zinc and lipid peroxidation in pregnant women with preeclampsia in gorgan. Open Biochem. J. 2014, 8, 83-88. [CrossRef] [PubMed]

87. Vafaei, H.; Dalili, M.; Hashemi, S.A. Serum concentration of calcium, magnesium and zinc in normotensive versus preeclampsia pregnant women: A descriptive study in women of Kerman province of Iran. Iran. J. Reprod. Med. 2015, 13, 23-26. [PubMed]

88. Ahsan, T.; Banu, S.; Nahar, Q.; Ahsan, M.; Khan, M.N.; Islam, S.N. Serum trace elements levels in preeclampsia and eclampsia: Correlation with the pregnancy disorder. Biol. Trace Elem. Res. 2013, 152, 327-332. [CrossRef] [PubMed]

89. Rathore, S.; Gupta, A.; Batra, H.S.; Rathore, R. Comparative study of trace elements and serum ceruloplasmin level in normal and pre-eclamptic pregnancies with their cord blood. Biomed. Res. 2011, 22, 207-210.

90. Kolusari, A.; Kurdoglu, M.; Yildizhan, R.; Adali, E.; Edirne, T.; Cebi, A.; Demir, H.; Yoruk, I.H. Catalase activity, serum trace element and heavy metal concentrations, and vitamin A, D and E levels in pre-eclampsia. J. Int. Med. Res. 2008, 36, 1335-1341. [CrossRef] [PubMed]

91. Atamer, Y.; Kocyigit, Y.; Yokus, B.; Atamer, A.; Erden, A.C. Lipid peroxidation, antioxidant defense, status of trace metals and leptin levels in preeclampsia. Eur. J. Obstet. Gynecol. Reprod. Biol. 2005, 119, 60-66. [CrossRef] [PubMed]

92. Adam, B.; Malatyalioglu, E.; Alvur, M.; Talu, C. Magnesium, zinc and iron levels in pre-eclampsia. J. Matern. Fetal Med. 2001, 10, 246-250. [CrossRef] [PubMed] 
93. Vigeh, M.; Yokoyama, K.; Ramezanzadeh, F.; Dahaghin, M.; Sakai, T.; Morita, Y.; Kitamura, F.; Sato, H.; Kobayashi, Y. Lead and other trace metals in preeclampsia: A case-control study in Tehran, Iran. Environ. Res. 2006, 100, 268-275. [CrossRef] [PubMed]

94. Carmichael, S.L.; Yang, W.; Shaw, G.M.; National Birth Defects Prevention Sdudy. Maternal dietary nutrient intake and risk of preterm delivery. Am. J. Perinatol. 2013, 30, 579-588. [PubMed]

95. Hsu, W.-Y.; Wu, C.-H.; Hsieh, C.T.-C.; Lo, H.-C.; Lin, J.-S.; Kao, M.-D. Low body weight gain, low white blood cell count and high serum ferritin as markers of poor nutrition and increased risk for preterm delivery. Asia Pac. J. Clin. Nutr. 2013, 22, 90-99. [PubMed]

96. Wang, H.; Hu, Y.-F.; Hao, J.-H.; Chen, Y.-H.; Wang, Y.; Zhu, P.; Zhang, C.; Xu, Y.-Y.; Tao, F.-B.; Xu, D.-X. Maternal serum zinc concentration during pregnancy is inversely associated with risk of preterm birth in a Chinese population. J. Nutr. 2016, 146, 509-515. [CrossRef] [PubMed]

97. Bo, S.; Lezo, A.; Menato, G.; Gallo, M.-L.; Bardelli, C.; Signorile, A.; Berutti, C.; Massobrio, M.; Pagano, G.F. Gestational hyperglycemia, zinc, selenium, and antioxidant vitamins. Nutrition 2005, 21, 186-191. [CrossRef] [PubMed]

98. Behboudi-Gandevani, S.; Safary, K.; Moghaddam-Banaem, L.; Lamyian, M.; Goshtasebi, A.; Goshtasbi, A.; Alian-Moghaddam, N. The relationship between maternal serum iron and zinc levels and their nutritional intakes in early pregnancy with gestational diabetes. Biol. Trace Elem. Res. 2013, 154, 7-13. [CrossRef] [PubMed]

99. Wibell, L.; Gebre-Medhin, M.; Lindmark, G. Magnesium and zinc in diabetic pregnancy. Acta Paediatr. Scand. Suppl. 1985, 320, 100-106. [CrossRef] [PubMed]

100. Al-Saleh, E.; Nandakumaran, M.; Al-Shammari, M.; Al-Harouny, A. Maternal-fetal status of copper, iron, molybdenum, selenium and zinc in patients with gestational diabetes. J. Matern. Fetal Neonatal Med. 2004, 16, 15-21. [CrossRef] [PubMed]

101. Prema, K.; Ramalakshmi, B.A.; Babu, S. Serum copper and zinc in hormonal contraceptive users. Fertil. Steril. 1980, 33, 267-271. [CrossRef]

102. Kristal, A.R.; Peters, U.; Potter, J.D. Is it time to abandon the food frequency questionnaire? Cancer Epidemiol. Biomark. Prev. 2005, 14, 2826-2828. [CrossRef] [PubMed]

103. Jackson, M. Physiology of zinc: General aspects. In Zinc in Human Biology; Springer: London, UK, 1989; pp. 1-14.

104. Goode, H.F.; Kelleher, J.; Walker, B.E. The effects of acute infection on indices of zinc status. Clin. Nutr. 1991, 10, 55-59. [CrossRef]

105. Halsted, J.A.; Hackley, B.M.; Smith, J.C., Jr. Plasma-zinc and copper in pregnancy and after oral contraceptives. Lancet 1968, 2, 278-279. [CrossRef]

106. Prasad, A.S. Clinical, endocrinological and biochemical effects of zinc deficiency. Clin. Endocrinol. Metab. 1985, 14, 567-589. [CrossRef]

107. Singh, A.; Smoak, B.L.; Patterson, K.Y.; LeMay, L.G.; Veillon, C.; Deuster, P.A. Biochemical indices of selected trace minerals in men: Effect of stress. Am. J. Clin. Nutr. 1991, 53, 126-131. [PubMed]

108. Moran, V.H.; Skinner, A.L.; Medina, M.W.; Patel, S.; Dykes, F.; Souverein, O.W.; Dullemeijer, C.; Lowe, N.M. The relationship between zinc intake and serum/plasma zinc concentration in pregnant and lactating women: A systematic review with dose-response meta-analyses. J. Trace Elem. Med. Biol. 2012, 26, 74-79. [CrossRef] [PubMed]

109. Benes, B.; Spevackova, V.; Smid, J.; Batariova, A.; Cejchanova, M.; Zitkova, L. Effects of age, BMI, smoking and contraception on levels of $\mathrm{Cu}$, Se and $\mathrm{Zn}$ in the blood of the population in the Czech Republic. Cent. Eur. J. Public Health 2005, 13, 202-207. [PubMed]

110. Ghayour-Mobarhan, M.; Taylor, A.; New, S.A.; Lamb, D.J.; Ferns, G.A. Determinants of serum copper, zinc and selenium in healthy subjects. Ann. Clin. Biochem. 2005, 42, 364-375. [CrossRef] [PubMed]

111. North, R.A.; McCowan, L.M.; Dekker, G.A.; Poston, L.; Chan, E.H.; Stewart, A.W.; Black, M.A.; Taylor, R.S.; Walker, J.J.; Baker, P.N.; et al. Clinical risk prediction for pre-eclampsia in nulliparous women: Development of model in international prospective cohort. BMJ 2011, 342, d1875. [CrossRef] [PubMed]

112. Kenny, L.C.; Black, M.A.; Poston, L.; Taylor, R.; Myers, J.E.; Baker, P.N.; McCowan, L.M.; Simpson, N.A.; Dekker, G.A.; Roberts, C.T.; et al. Early pregnancy prediction of preeclampsia in nulliparous women, combining clinical risk and biomarkers: The Screening for Pregnancy Endpoints (SCOPE) international cohort study. Hypertension 2014, 64, 644-652. [CrossRef] [PubMed] 
113. Brown, K.H.; Rivera, J.A.; Bhutta, Z.; Gibson, R.S.; King, J.C.; Lonnerdal, B.; Ruel, M.T.; Sandtrom, B.; Wasantwisut, E.; Hotz, C. International Zinc Nutrition Consultative Group (IZiNCG) technical document \#1. Assessment of the risk of zinc deficiency in populations and options for its control. Food Nutr. Bull. 2004, 25, S99-S203. [PubMed]

114. Burton, G.J.; Jauniaux, E. Placental oxidative stress: From miscarriage to preeclampsia. J. Soc. Gynecol. Investig. 2004, 11, 342-352. [CrossRef] [PubMed]

115. Marklund, S. Distribution of CuZn superoxide dismutase and Mn superoxide dismutase in human tissues and extracellular fluids. Acta Physiol. Scand. Suppl. 1980, 492, 19-23. [PubMed]

116. Bruno, R.S.; Song, Y.; Leonard, S.W.; Mustacich, D.J.; Taylor, A.W.; Traber, M.G.; Ho, E. Dietary zinc restriction in rats alters antioxidant status and increases plasma F2 isoprostanes. J. Nutr. Biochem. 2007, 18, 509-518. [CrossRef] [PubMed]

117. Oteiza, P.I.; Clegg, M.S.; Zago, M.P.; Keen, C.L. Zinc deficiency induces oxidative stress and AP-1 activation in 3 T3 cells. Free Radic. Biol. Med. 2000, 28, 1091-1099. [CrossRef]

118. Prasad, A.S.; Beck, F.W.; Bao, B.; Fitzgerald, J.T.; Snell, D.C.; Steinberg, J.D.; Cardozo, L.J. Zinc supplementation decreases incidence of infections in the elderly: Effect of zinc on generation of cytokines and oxidative stress. Am. J. Clin. Nutr. 2007, 85, 837-844. [PubMed]

119. Sankavaram, K.; Chong, L.; Bruno, R.S.; Freake, H.C. Zinc status alters growth and oxidative stress responses in rat hepatoma cells. Nutr. Cancer 2014, 66, 104-116. [CrossRef] [PubMed]

120. Song, Y.; Leonard, S.W.; Traber, M.G.; Ho, E. Zinc deficiency affects DNA damage, oxidative stress, antioxidant defenses, and DNA repair in rats. J. Nutr. 2009, 139, 1626-1631. [CrossRef] [PubMed]

121. Habib, Z.; Abdulla, M. Plasma levels of zinc, copper, magnesium and calcium during early weeks of gestation. Acta Pharmacol. Toxicol. 1986, 59 (Suppl. 7), 602-605. [CrossRef]

122. Donangelo, C.M.; Zapata, C.L.; Woodhouse, L.R.; Shames, D.M.; Mukherjea, R.; King, J.C. Zinc absorption and kinetics during pregnancy and lactation in Brazilian women. Am. J. Clin. Nutr. 2005, 82, 118-124. [PubMed]

123. Fung, E.B.; Ritchie, L.D.; Woodhouse, L.R.; Roehl, R.; King, J.C. Zinc absorption in women during pregnancy and lactation: A longitudinal study. Am. J. Clin. Nutr. 1997, 66, 80-88. [PubMed]

124. Sherwood, L. Human Physiology: From Cells to Systems; Cengage Learning: Boston, MA, USA, 2015.

125. Bowen, J.M.; Chamley, L.; Keelan, J.A.; Mitchell, M.D. Cytokines of the placenta and extra-placental membranes: Roles and regulation during human pregnancy and parturition. Placenta 2002, 23, 257-273. [CrossRef] [PubMed]

126. Allen, L.H. Multiple micronutrients in pregnancy and lactation: An overview. Am. J. Clin. Nutr. 2005, 81, 1206S-1212S. [PubMed]

127. Christian, P.; West, K.P., Jr. Interactions between zinc and vitamin A: An update. Am. J. Clin. Nutr. 1998, 68, 435S-441S. [PubMed]

128. Lonnerdal, B. Dietary factors influencing zinc absorption. J. Nutr. 2000, 130, 1378S-1383S. [PubMed]

129. Solomons, N.W. Competitive interaction of iron and zinc in the diet: Consequences for human nutrition. J. Nutr. 1986, 116, 927-935. [PubMed]

(c) 2016 by the authors; licensee MDPI, Basel, Switzerland. This article is an open access article distributed under the terms and conditions of the Creative Commons Attribution (CC-BY) license (http://creativecommons.org/licenses/by/4.0/). 